LBNL-43526

\title{
Site S-7 VOC Transport Modeling for the Vadose Zone Monitoring System (VZMS), McClellan AFB 1999 Semi-Annual Report
}

\author{
Christine Doughty, Curtis M. Oldenburg, and April L. James
}

Earth Sciences Division

Ernest Orlando Lawrence Berkeley National Laboratory

Berkeley, CA 94720

June 15, 1999

This work was supported by the U.S. Department of Defense under Military Interdepartmental Purchase Request FD2040-96-74020EM to the Ernest Orlando Lawrence Berkeley National Laboratory, managed for the U.S.

Department of Energy under contract DE-AC03-76SF00098. 


\section{DISCLAIMER}

This report was prepared as an account of work sponsored by an agency of the United States Government. Neither the United States Government nor any agency thereof, nor any of their employees, make any warranty, express or implied, or assumes any legal liability or responsibility for the accuracy, completeness, or usefulness of any information, apparatus, product, or process disclosed, or represents that its use would not infringe privately owned rights. Reference herein to any specific commercial product, process, or service by trade name, trademark, manufacturer, or otherwise does not necessarily constitute or imply its endorsement, recommendation, or favoring by the United States Government or any agency thereof. The views and opinions of authors expressed herein do not necessarily state or reflect those of the United States Government or any agency thereof. 


\section{DISCLAIMER}

\section{Portions of this document may be illegible in electronic image products. Images are produced from the best available original document.}




\section{TABLE OF CONTENTS}

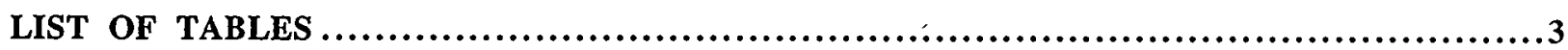

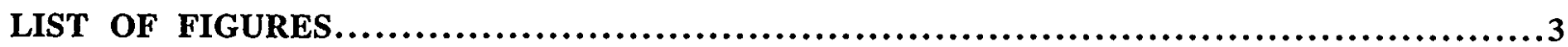

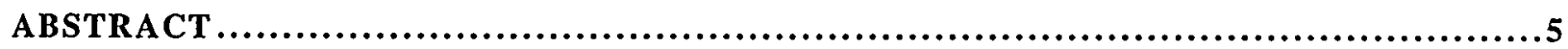

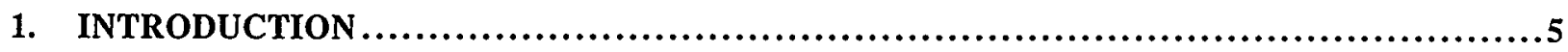

2. TEMPERATURE MODELING......................................................6

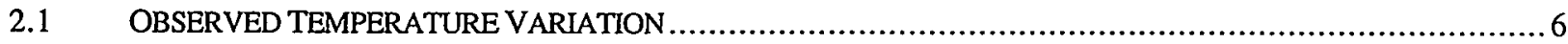

2.2 ANALYTICAL SOLUTION FOR CONDUCTIVE HEAT TRANSPORT ...........................................

2.3 POTENTIAL TEMPERATURE EFFECTS ON VOC TRANSPORT ................................................... 10

3. VOC TRANSPORT MODELING................................................ 10

3.1 OBSERVED GAS-PHASE VOC CONCENTRATIONS......................................................... 10

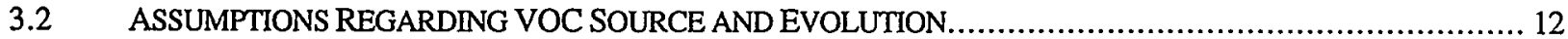

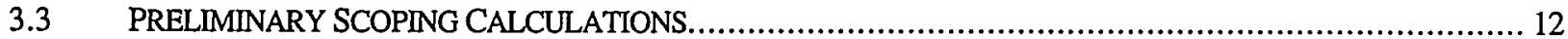

3.4 CONCEPTUAL MODELS FOR SUBSURFACE FLOW AND TRANSPORT............................................. 14

4. EVALUATION AND DISCUSSION OF CONCEPTUAL MODELS....................... 17

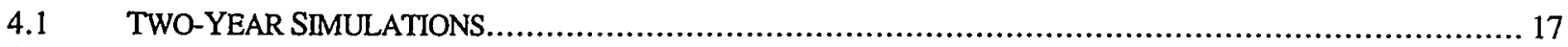

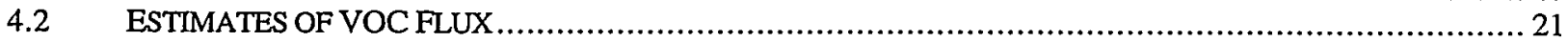

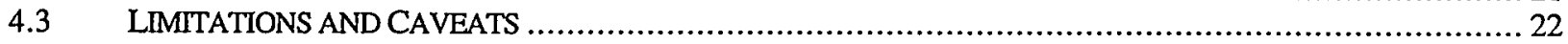

5. DISCUSSION OF PRIOR VAPOURT RESULTS................................... 22

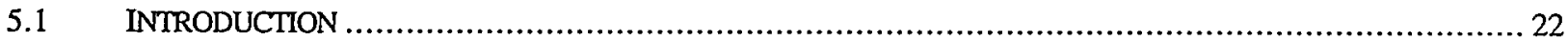

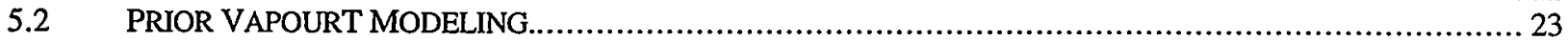

5.3 DISCUSSION AND COMPARISON TO VZMS RESULTS................................................................. 24

6. SUMMARY AND CONCLUSIONS................................................ 26

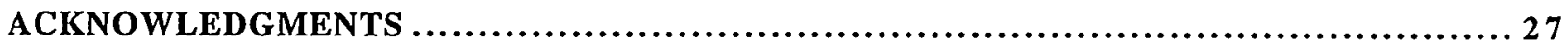

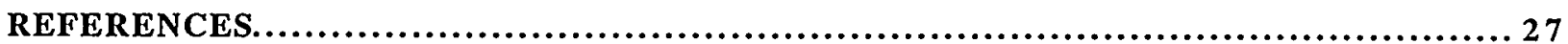




\section{LIST OF TABLES}

Table 2.1. Summary of parameters used in temperature modeling. 9

Table 4.1. TCE fluxes $\left(\mathrm{kg} \mathrm{m}^{-2} \mathrm{yr}^{-1}\right)$ calculated by T2VOC at the end of two-year simulations.... 22

\section{LIST OF FIGURES}

Figure 1.1. Map of site S-7.

Figure 2.1. Daily average air temperature at McClellan AFB from May 1997 through December 1998 32

Figure 2.2. Subsurface temperatures measured in Wells VZMS-A and VZMS-B from May 1997 through December 1998 32

Figure 2.3. Comparison of observed subsurface temperatures with analytical solution for conductive heat transfer.

Figure 2.4. Comparison of observed air temperature with sinusoidal ground surface temperature obtained by fitting analytical solution to subsurface temperatures, as shown in Figure 2.3.

Figure 2.5. Temperature versus depth profiles for several times. 35

Figure 3.1. (a) Gas-phase TCE concentration-depth profiles observed in Wells VZMS-A and VZMS-B at a series of times between May 1997 and May 1999; (b) Gas-phase TCE concentrations as a function of time for shallow observation depths.

Figure 3.2. (a) Gas-phase cis-1,2-DCE concentration-depth profiles observed in Wells VZMS-A and VZMS-B at a series of times between May 1997 and May 1999; (b) Gas-phase cis1,2-DCE concentrations as a function of time for shallow observation depths.

Figure 3.3. Simulated liquid saturation profile (green) and gas-phase TCE concentration profiles at the innermost column of an $(r, z)$ model for a 30-year simulation of TCE evolution... 38

Figure 3.4. Simulated liquid saturation profile (green) and gas-phase TCE concentration profiles at the innermost column of an $(r, z)$ model for a 30-year simulation of TCE evolution with no liquid infiltration and immobile water..

Figure 3.5. Conceptual models for subsurface flow and transport beneath site S-7. (a) Layered single-continuum model; (b) Layered dual-continua model with preferential flow paths (PFPs) and isolated sediment blocks (ISBs); (c) Anisotropic single-continuum model... 40 
Figure 4.1. Gas-phase TCE concentration profiles for 1997-1999 simulation with singlecontinuum model, no NAPL in source.

Figure 4.2. Gas-phase TCE concentration versus time for 1997-1999 simulation with singlecontinuum model, no NAPL in source

Figure 4.3. Gas-phase TCE concentration profiles for 1997-1999 simulation with singlecontinuum model, NAPL in source.

Figure 4.4. Gas-phase TCE concentration versus time for 1997-1999 simulation with singlecontinuum model, NAPL in source

Figure 4.5. Gas-phase TCE concentration profiles for 1997-1999 simulation with dual-continua model, NAPL in source. (a) PFPs; (b) ISBs.

Figure 4.6. Gas-phase TCE concentration versus time for 1997-1999 simulation with dualcontinua model, NAPL in source..................................................................... 47

Figure 4.7. Gas-phase TCE concentration versus time for 1997-1999 simulation with singlecontinuum model, NAPL in source, and sinusoidally varying surface temperature....... 48

Figure 4.8. Atmospheric pressure variation during 1997-1999 at site S-7 ............................. 49

Figure 4.9. Gas-phase TCE concentration versus time for 1997-1999 simulation with singlecontinuum model, NAPL in source, and variable atmospheric pressure.

Figure 4.10. (a) Daily precipitation for McClellan AFB; (b) Monthly average of daily precipitation. Gaps in the McClellan precipitation record are filled in with data from the Sacramento Airport and the Sacramento Post Office.

Figure 4.11. Gas-phase TCE concentration versus time for 1997-1999 simulation with singlecontinuum model, NAPL in source, and variable infiltration rate 


\section{ABSTRACT}

Enhanced data analysis is continuing for the Vadose Zone Monitoring System (VZMS) installed at site S-7 in IC 34 at McClellan AFB. Air temperatures along with data from the four highest levels of thermistors in VZMS-A and B are used with an analytical solution for the heat conduction equation to show that heat transfer in the shallow vadose zone at S-7 is conductiondominated. This analysis is extended to reveal that surface temperature, i.e., the temperature of the concrete slab at S-7, is significantly higher in summer than the surrounding air temperature. These high temperatures in the shallow vadose zone can lead to increased volatilization of VOCs. Seasonal temperature reversals can cause upward buoyant gas flow in the uppermost 30 feet of the vadose zone in the winter. Data on gas-phase VOC concentrations in VZMS-A and B show highest concentrations in the shallow subsurface, low concentrations between depths of 30-70 feet, and slightly higher concentrations near the water table. Modeling VOC flow and transport subject to the constraints of data collected by the VZMS requires extension of the onedimensional site-representative model used previously. Conceptual models broadly consistent with these data include (1) a diffusion-only model; (2) a preferential flow model; or (3) two- and three-dimensional flow models where the VOC plume undergoes lateral migration. Simulations of VOC transport suggest that there are VOCs at depths shallower than 6 feet, that significant NAPL is unlikely to be present, and that a source of VOCs may be provided by lateral flow in the gravel layer between two concrete layers present at the site. The conceptual models upon which VOC transport modeling is based require further development and testing. Prior VapourT modeling results for the S-7 site based on cis-1,2-DCE concentrations in well SS7SB08 are not substantiated by VZMS data, but these data are localized whereas VapourT results are generalized for the S-7 site as a whole. Future work will incorporate data from VZMS-C to further constrain the S-7 conceptual model. We recommend further studies to develop dualcontinua or two- or three-dimensional models with associated characterization data to simulate VOC transport at S-7.

\section{INTRODUCTION}

In this report, we present further enhanced data analysis for the VZMS (LBNL, 1996) installed at the S-7 site in IC 34 at McClellan AFB (Figure 1.1). Enhanced data analysis described in prior semi-annual reports (LBNL, 1998b; 1998c) used VZMS pressure data along with atmospheric pressure to estimate formation permeability by numerical inversion using T2VOC (Falta et al., 1995) and ITOUGH2 (Finsterle, 1997). We also used laboratory data taken 
from cores for moisture retention of sediments in one-dimensional simulations using a site S-7 representative model, and found good agreement with neutron probe data for moisture content assuming constant $100 \mathrm{~mm} / \mathrm{yr}$ recharge (LBNL, 1998c). With the understanding of the flow properties of the vadose zone at S-7 developed over the last year, we now direct our investigation toward heat and mass transport and their implications for volatile organic chemical (VOC) migration in the vadose zone at S-7.

This report is divided into sections reporting on different aspects of the data analysis. In Section 2, we model VZMS temperature data using an analytical solution to the conduction equation to infer thermal properties and temporal variations in heat transfer that may influence volatilization and transport of VOCs. We discuss how temperature effects are limited to the shallowest parts of the vadose zone, the same regions in S-7 that show the largest VOC contaminant concentrations. In Section 3, the VZMS data on gas-phase concentrations of TCE and cis-1,2-DCE are reviewed. We present model results from different conceptual models for the flow and transport of VOCs that are consistent with these VOC concentration data. In Section 4, various conceptual models for VOC flow and transport are discussed and evaluated using T2VOC simulation results. A brief review and assessment of prior VapourT modeling at S7 is presented in Section 5 in light of our VZMS data and enhanced data analysis. Conclusions are presented in Section 6 .

\section{TEMPERATURE MODELING}

\subsection{Observed Temperature Variation}

The VZMS has been collecting continuous temperature data from 13 levels in two boreholes at the S-7 site for two years. In this section, these data are used along with enhanced data analysis and McClellan AFB air-temperature data to examine heat transfer processes in the vadose zone at S-7. In Figure 2.1 we present the daily average air temperature measured at McClellan AFB from May 1997 through December 1998 (NOAA, 1999), which illustrates the combination of short-term temperature fluctuations and gradual seasonal variation typical of midlatitude climates. Figure 2.2 shows the temperatures measured in VZMS-A and VZMS-B at depths of $6,11,18$, and 30 feet for the same time period. Note that strong temperature variations are present at a depth of 6 feet, and that they become smaller and smoother as depth increases, until at 30 feet the temperature is nearly constant. 


\subsection{Analytical Solution for Conductive Heat Transport}

We can model the subsurface temperature variation in space and time by considering onedimensional conductive heat transfer from a specified temperature boundary condition at the ground surface. The equation governing such heat flow may be written as

$$
\frac{\partial T}{\partial t}=\frac{\lambda}{C} \frac{\partial^{2} T}{\partial z^{2}}
$$

where $\lambda$ is the thermal conductivity and $C$ is the volumetric heat capacity of the subsurface (Hillel, 1980). If we assume a homogeneous medium ( $\lambda$ and $C$ uniform) and a sinusoidally varying surface temperature, then an analytical solution is available to describe the subsurface temperature distribution $T(z, t)$. We assume a surface temperature of the form

$$
T_{\text {surf }}=T_{0}+T_{1} \cos \left[\omega\left(t-t_{0}\right)\right]
$$

where $\omega=2 \pi / \tau$, and $\tau$ is the period of the temperature variation. $T_{0}$ is the average temperature, $T_{1}$ is the amplitude of the temperature variation, and $t_{0}$ is a phase constant used to identify the time at which temperature is a maximum. Then the subsurface temperature distribution is

$$
T(z, t)=T_{0}+T_{1} \exp (-z / D) \cos \left[\omega\left(t-t_{0}\right)-z / D\right],
$$

where

(Hillel, 1980).

$$
D=\left(\frac{2 \lambda}{\omega C}\right)^{1 / 2}
$$

Equation (2.3) shows a damping of the surface signal with depth through the exponential term and a phase lag that also depends on depth. Both processes are controlled by the parameter $D$, which depends directly on thermal conductivity $\lambda$ and inversely on $\omega$, the frequency of the temperature variation. Thus for longer period temperature variations, surface temperature variations will propagate farther into the subsurface. This effect is apparent in the field data in that the seasonal temperature variation is observed all the way down to depths of 30 feet, whereas the short-term variations (with periods of a few days to a week) are barely visible at a depth of 6 feet (Figure 2.2). Hence, we first consider just the seasonal temperature variation, and take $\tau=365$ days in Equation (2.4). We vary the unknown parameters $T_{0}, T_{1}, D$, and $t_{0}$ by hand to obtain the best match possible to the long-term features of the subsurface temperatures shown in Figure 2.2. Using the parameters $T_{0}=21.3^{\circ} \mathrm{C}, T_{1}=15^{\circ} \mathrm{C}, t_{0}=190$ days (July 9, 1997), and $D=2.2 \mathrm{~m}$ yields the matches shown in Figure 2.3. The match is very good, suggesting that 
subsurface heat transfer in the vadose zone at the S-7 site is in fact conduction-dominated, and the thermal diffusivity, $\lambda / C$ is well approximated by a constant value. A comparably good match is obtained for $T_{0}=21.3^{\circ} \mathrm{C}, T_{1}=13{ }^{\circ} \mathrm{C}, t_{0}=200$ days (July 19,1997 ), and $D=2.4 \mathrm{~m}$, providing an estimate of the range of uncertainty of the inferred parameter values. To determine thermal conductivity $\lambda$ from $D$, we must first determine $C$, volumetric heat capacity, which is defined as

$$
C=(1-\phi) \rho_{\mathrm{r}} c_{\mathrm{r}}+\phi\left(S_{1} \rho_{1} c_{\mathrm{l}}+S_{\mathrm{g}} \rho_{\mathrm{g}} c_{\mathrm{g}}\right)
$$

where $\phi$ is porosity, $S$ is saturation, $\rho$ is density and $c$ is specific heat. The subscripts $r$, l, and $g$ correspond to rock, liquid water, and gas, respectively. Because the density and specific heat of gas is small compared to that of rock or liquid water, we ignore the final term in Equation (2.5). We take average values of $\phi, S_{\mathrm{l}}$, and $\rho_{\mathrm{r}}$ from the site S-7 representative model (LBNL, 1998c), and approximate values for $c_{\mathrm{r}}, \rho_{\mathrm{l}}$, and $c_{\mathrm{l}}$. Using $\phi=0.47, S_{1}=0.7, \rho_{\mathrm{r}} c_{\mathrm{r}}=1.5 \mathrm{MJ} \mathrm{m}^{-3}{ }^{\circ} \mathrm{C}^{-1}$, and $\rho_{1}$ $c_{1}=4 \mathrm{MJ} \mathrm{m}^{-3}{ }^{\circ} \mathrm{C}^{-1}$ yields $C=2.1 \mathrm{MJ} \mathrm{m}^{-3}{ }^{\circ} \mathrm{C}^{-1}$. Equation (2.4) yields $\lambda=1-1.2 \mathrm{~W} \mathrm{~m}^{-1}{ }^{\circ} \mathrm{C}^{-1}$ for $D$ $=2.2-2.4 \mathrm{~m}$. The values of the parameters used in Equations (2.3) through (2.5) are summarized in Table 2.1 .

Note that for seasonal temperature variations, with $D=2.2 \mathrm{~m}$, the damping term is $\exp (-$ $z / D)=0.01$ at a depth of 33 feet $(10.1 \mathrm{~m})$. This may be considered the penetration depth of the seasonal temperature variation into the subsurface. In contrast, for a daily temperature variation, $\omega$ in Equation (2.4) increases by a factor of $365, D=0.115 \mathrm{~m}$, and the penetration depth is only 1.7 feet $(0.5 \mathrm{~m})$. The deviations from sinusoidal behavior seen in the subsurface temperatures observed at the 6-feet depth (Figure 2.3) reflect the propagation of surface temperature variations lasting a few days to a few weeks, known as synoptic temperature variations. If it is desired to focus on this behavior, it is possible to model numerically the propagation of temperature changes through the subsurface without assuming an idealized surface temperature of the form of Equation (2.2). This is done by prescribing the observed temperature variation at a given depth as a model boundary condition, and comparing predicted and observed temperature variations at greater depths. Such a simulation was not done for the present study, because the overall character of the temperature variation is well described by Equation (2.3).

Figure 2.4 compares the daily average air temperature observed at McClellan AFB with the surface temperature given by Equation (2.2) using the best-fit values of $T_{0}, T_{1}$, $t_{0}$, and $D$ obtained from matching the subsurface temperatures. It is clear that although the long-term variation of the daily average air temperature does have a sinusoidal form, the surface temperature significantly exceeds the daily average air temperature during the summer months. This is consistent with everyday experience for non-vegetated places in warm climates. This points out 
the value of using subsurface temperatures to estimate average surface temperature, a quantity not easily measured in the field.

Figure 2.5 shows temperature versus depth profiles for several times. Note the seasonal reversal of temperature gradient near the ground surface, which implies a reversal in the direction of heat flow. It is also of interest to note that the groundwater temperature $\left(20.5^{\circ} \mathrm{C}\right)$ is slightly cooler than the average vadose zone temperature $\left(T_{0}=21.3^{\circ} \mathrm{C}\right)$, suggesting that the largely-paved McClellan AFB site acts as a "heat island," compared to the surrounding agricultural land under which the groundwater flows.

Table 2.1 Summary of Parameters used in Temperature Modeling

\begin{tabular}{|c|c|c|}
\hline Parameter & Value & Source \\
\hline Average surface temperature, $T_{0}$ & $21.3^{\circ} \mathrm{C}$ & Inferred by fitting $T(z, t)$ data \\
\hline $\begin{array}{l}\text { Amplitude of surface temperature } \\
\text { variation, } T_{1}\end{array}$ & $13-15^{\circ} \mathrm{C}$ & Inferred by fitting $T(z, t)$ data \\
\hline $\begin{array}{l}\text { Time of maximum surface } \\
\text { temperature, } t_{0}\end{array}$ & July $9-$ July 19 & Inferred by fitting $T(z, t)$ data \\
\hline $\begin{array}{l}\text { Damping parameter for seasonal } \\
\text { temperature variations, } D\end{array}$ & $2.2-2.4 \mathrm{~m}$ & Inferred by fitting $T(z, t)$ data \\
\hline Volumetric heat capacity, $C$ & $2.1 \mathrm{MJ} \mathrm{m}^{-3}{ }^{\circ} \mathrm{C}^{-1}$ & Calculated from Equation (2.5) \\
\hline Average porosity, $\phi$ & 0.47 & Representative Site S-7 model \\
\hline Average liquid saturation, $S_{1}$ & 0.7 & Representative Site S-7 model \\
\hline Average sediment density, $\rho_{r}$ & $1500 \mathrm{~kg} \mathrm{~m}^{-3}$ & Representative Site S-7 model \\
\hline Average sediment specific heat, $c_{\mathrm{r}}$ & $1000 \mathrm{~J} \mathrm{~kg}^{-1}{ }^{\circ} \mathrm{C}^{-1}$ & Approximate value \\
\hline Liquid water density, $\rho_{1}$ & $1000 \mathrm{~kg} \mathrm{~m}^{-3}$ & Approximate value \\
\hline Liquid water specific heat, $c_{1}$ & $4000 \mathrm{~J} \mathrm{~kg}^{-1}{ }^{\circ} \mathrm{C}^{-1}$ & Approximate value \\
\hline Thermal conductivity, $\lambda$ & $1-1.2 \mathrm{~W} \mathrm{~m}^{-1}{ }^{\circ} \mathrm{C}^{-1}$ & Calculated from Equation (2.4) \\
\hline $\begin{array}{l}\text { Damping parameter for daily } \\
\text { temperature variations, } D \mathrm{~d}\end{array}$ & $0.12-0.13 \mathrm{~m}$ & $\begin{array}{l}\text { Calculated from Equation ( } 2.4 \text { ), } \\
\text { substituting a period of } 1 \text { day for a } \\
\text { period of } 365 \text { days }\end{array}$ \\
\hline $\begin{array}{l}\text { Penetration depth for seasonal } \\
\text { temperature variations }\end{array}$ & $10-11 \mathrm{~m}$ & Depth for which $\exp (-z / D)=0.01$ \\
\hline $\begin{array}{l}\text { Penetration depth for daily } \\
\text { temperature variations }\end{array}$ & $0.5-0.6 \mathrm{~m}$ & Depth for which $\exp (-z / D d)=0.01$ \\
\hline
\end{tabular}




\subsection{Potential Temperature Effects on VOC Transport}

The highest expected temperatures at McClellan AFB (a seasonal maximum surface temperature of $36^{\circ} \mathrm{C}$, with an estimated daily maximum surface temperature of $46^{\circ} \mathrm{C}$ ) are well below the boiling point of TCE $\left(\sim 87^{\circ} \mathrm{C}\right)$. However, if NAPL is present, its volatility will change within this range of observed temperatures leading to higher gas-phase and aqueous-phase concentrations of TCE as temperature increases. If NAPL is not present, temperature increases will cause TCE to partition more strongly into the gas phase relative to the aqueous phase, leading to higher gas-phase concentrations. Because gas-phase TCE is more mobile than aqueousphase TCE, and both phases are more mobile than NAPL in the vadose zone, temperature can affect the transport of TCE. However, over the course of a year, subsurface temperatures spend just as much time below the average temperature as above it, so the enhanced transport of TCE accompanying higher temperatures during part of the year is balanced by diminished transport occurring at lower than average temperatures during other parts of the year. Therefore, the overall effect of seasonal subsurface temperature variations on TCE transport due to variation in volatility is expected to be small.

Another potential temperature effect is through buoyancy flow. In the gas-phase, for a given temperature and pressure, soil gas containing high concentrations of TCE is denser than ambient air and thus will tend to sink (Falta et al., 1989). During fall and winter, when reversals in temperature gradients make the surface cooler than the shallow subsurface (e.g., Figure 2.5) upward buoyancy flow of soil gas containing TCE from the shallow vadose zone to the atmosphere may occur. Combined with gas-phase diffusion, which always drives TCE from regions of high to low concentration, this process can lead to outgassing of shallow subsurface VOC contamination.

\section{VOC TRANSPORT MODELING}

\subsection{Observed Gas-Phase VOC Concentrations}

Data on VOC concentrations from VZMS-A and B collected over the last two years can be used to constrain conceptual models of VOC transport in the vadose zone at the S-7 site. Figures 3.1 and 3.2 show gas-phase concentrations of TCE and cis-1,2-DCE, respectively. Generally, we find that gas-phase and aqueous-phase VOC concentrations are in equilibrium according to Henry's law (LBNL, 1998a). These concentrations are several of orders of magnitude smaller 
than would be found in a gas phase that is in equilibrium with bulk NAPL. Note that TCE and cis-1,2-DCE show the same general vertical profiles except just above the water table where cis1,2-DCE concentrations decline. Hence, for the present studies we assume that the parent-daughter transformation from TCE to cis-1,2-DCE is fast relative to transport and residence times. Thus, we assume that TCE and cis-1,2-DCE are in equilibrium and we focus on the TCE gas-phase concentrations as constraints on VOC transport models for the S-7 site.

There are several noteworthy features in the TCE spatial distribution (Figure 3.1a), including (1) a sharp concentration gradient near the surface (concentration decreases from about $100 \mathrm{ppmv}$ to less than 1 ppmv over about 25 feet), (2) a zone of low concentrations (depths from 30 to 70 feet), and (3) a gradual concentration increase toward the water table (depths from 70 to 112 feet). Note that VZMS-A and B show very similar concentration profiles, demonstrating the reliability of our sample collection methods and suggesting local lateral continuity of the lithologic features controlling transport. However, data reported by Jacobs (1998) from a one-time soil-gas sampling event for the nearby well SS7SB08 (Figure 1.1) show markedly different concentration profiles, with cis-1,2-DCE concentrations at 50-100 ppmv at depths of 30-40 feet, suggesting that vadose zone contamination may be strongly heterogeneous. The fluvial geologic setting underlying McClellan AFB would be expected to show strong hydrologic heterogeneity, with the expression of buried stream channels providing highpermeability pathways, and flood-plain and overbank deposits potentially providing lowpermeability barriers to flow. There are inherent limitations in developing a model based on data from one-dimensional vertical boreholes for an intrinsically three-dimensional flow and transport problem. The challenges involved in conceptual model development will be further discussed in Section 3.4, below.

Another important feature of Figure 3.1a is the temporal variability in measurements. While most measurements at each depth fall within a band of width slightly less than an order of magnitude in concentration, the variability is at least an order of magnitude when you include all the data points. Although there does seem to be a systematic increase in concentration with time in the upper 25 feet or so (Figure 3.1b), suggesting that the TCE plume is moving downward, there is also a great deal of scatter around this trend. This scatter may be due to the method of sampling, rather than actual large, short-term changes in TCE concentration. Each gas sample requires extraction of a large volume of gas $(\sim 1$ liter). For typical porosity $(\phi=0.47)$ and liquid saturation $\left(S_{1}=0.7\right)$ values, this corresponds to a subsurface volume of about 7 liters. As the moisture distribution surrounding the extraction point changes over time, gas from different 
regions may be pulled into different samples, providing highly variable TCE concentrations, although the movement of TCE itself is limited.

\subsection{Assumptions Regarding VOC Source and Evolution}

The historical record of activities at Site S-7 is not sufficiently detailed to establish how VOCs were introduced to the vadose zone nor the chronology of the contamination. Therefore, to try to explain what is observed in the subsurface today, we have to make a number of assumptions about what happened in the past. In our preliminary scoping calculations, we assume that a source term consisting of several $\mathrm{kg}$ of TCE is present as NAPL at a depth of about 6 feet, 30 years before present. Then we model its evolution to the present day. No additional TCE is added to the system, but TCE may be lost from the system to the atmosphere and the underlying groundwater. Water infiltration occurs at a constant rate of $100 \mathrm{~mm} / \mathrm{yr}$, a value inferred from modeling present-day moisture distributions (LBNL, 1998c). TCE is transported by liquid and gas phase advection, gas-phase gravity flow and diffusion, and flow of the NAPL as a separate phase, and may also be adsorbed on sediments. We assume equilibrium partitioning of TCE between phases. More details on the physical processes involved in subsurface evolution of VOC are provided elsewhere (LBNL, 1998b; Falta et al., 1995).

\subsection{Preliminary Scoping Calculations}

Our initial attempts to model the 30-year evolution of TCE employed the one-dimensional Site S-7 representative model that was used to simulate liquid infiltration and propagation of atmospheric pressure variations into the subsurface (LBNL, 1998b, 1998c). This model includes a detailed representation of the lithology observed in both Wells VZMS-A and VZMS-B (Figure 5, LBNL, 1998c), and proved very successful at reproducing moisture contents and gas-phase pressures observed in the field. However, it is not adequate for simulating the long-term evolution of a TCE plume because it does not allow for the lateral dilution that occurs from the spreading of TCE away from a finite source. After 30 years of evolution, TCE concentrations in the one-dimensional model were several orders of magnitude higher than those observed in the VZMS wells. These results led us to develop a simple layered axisymmetric $(r, z)$ model by extending the layered lithology observed in Wells VZMS-A and B radially outward from the Site7 center. As noted in Section 3.1 above, such an extrapolation is not necessarily a good approximation for a fluvial geological setting, but in the absence of a detailed geological model, it provides a reasonable starting point for VOC modeling studies. This approach is similar to that 
taken by Jacobs Engineering in its modeling of VOC transport in the vadose zone using VapourT (Jacobs, 1998).

The radial grid spacing in the axisymmetric grid is quite coarse, with the innermost two grid blocks having a radial extent of $2 \mathrm{~m}$ ( 6.6 feet), and grid block radial extent doubling thereafter. The model contains a total of 6 radial "columns," and has a total radial extent of $64 \mathrm{~m}$ (210 feet). The vertical discretization is unchanged from the one-dimensional Site S-7 representative model, with $2250.15-\mathrm{m}$ ( 0.5 feet) thick layers (LBNL, 1998c). The TCE source is specified as a NAPL saturation of 0.006 in the innermost grid block at a depth of about 6 feet, which results in a mass of TCE of about $6 \mathrm{~kg}$. The outer radial boundary of the model is closed. The top boundary of the model is the atmosphere, which is modeled as a constant-pressure, constant-temperature boundary containing no mobile liquid water. The lower boundary of the model is the water table, which is modeled as a water-saturated, constant-pressure, constant-temperature boundary. Water infiltration is specified as a constant mass source in the uppermost layer of the model below the atmosphere, with a strength equivalent to $100 \mathrm{~mm} / \mathrm{yr}$. For comparison to the percolation rate used in VapourT modeling $\left(v=2.0 \times 10^{-9} \mathrm{~m} \mathrm{~s}^{-1}\right)$ (Jacobs, 1998), $100 \mathrm{~mm} / \mathrm{yr}$ corresponds to a percolation rate of $3.2 \times 10^{-9} \mathrm{~m} \mathrm{~s}^{-1}$.

Figure 3.3 shows the results of the $(r, z)$ model by displaying gas-phase TCE concentration profiles for the innermost column of the model at a series of times during the 30year simulation. The liquid saturation profile is also shown; it does not change in time as it represents an equilibrium between gravity flow of infiltrating water and capillary forces. Note that the 30-year concentration profile differs greatly from the observed profile shown in Figure 3.1a. In particular, the maximum concentration is not near the surface, but spread out over a range of depths well below it, presumably a result of liquid-phase advection of TCE dissolved in the aqueous phase that subsequently partitions into the gas-phase. In order to investigate the physical process producing the concentration profile, an additional 30-year simulation was done, this time assuming no liquid water infiltration by making water in the subsurface immobile. Figure 3.4 shows the results of this variation. As in Figure 3.3, the liquid saturation does not change in time, however in this case it is because no water movement at all occurs. Hence, the TCE transport occurs solely by gas-phase gravity flow and diffusion. Note the significant differences in the shape of the TCE concentration profiles in Figures 3.3 and 3.4. The profile shown in Figure 3.4 contains more of the features observed in the VZMS data (Figure 3.1a), with a maximum concentration at the depth of the source, and a sharply decreasing concentration below it. This suggests that liquid-phase advection of TCE may not be occurring below Site S-7, and that the shallow portion of the concentration profile is largely diffusion-controlled. 
Assuming the observed VZMS data and the assumptions underlying the modeling results are correct, we are faced with the question of how the TCE profile can show a diffusion-controlled shape, indicating negligible advective transport, and still allow the infiltration necessary to maintain liquid saturations consistent with neutron probe observations (LBNL, 1998c).

A series of sensitivity studies with the basic layered $(r, z)$ model proved unsuccessful at answering this question. For example, if we add a barrier to liquid flow (e.g., a caliche layer just below the NAPL source), we see drying below it, which is inconsistent with the observed moisture data. If we add gaps to the barrier to allow some liquid infiltration and thereby maintain liquid saturations, capillary forces cause the infiltrating water to flow laterally as it bends around the barrier and then advects TCE downward. If we change the amount or spatial distribution of TCE in the source, we can modify the shape of the concentration profile somewhat, but we cannot eliminate its advective nature while maintaining liquid saturations consistent with neutron probe measurements, tensiometer data, and moisture content measured in sediment cores (LBNL, 1998c; 1999). These observations led us to develop alternative conceptual models discussed in the following section.

\subsection{Conceptual Models for Subsurface Flow and Transport}

With the goal of matching both moisture content and VOC concentration data, we have investigated three alternative hypothetical conceptual models for VOC flow and transport. These conceptual models are shown schematically in Figure 3.5 and discussed in more detail below.

\section{Layered Single-Continuum Model}

The layered single-continuum model (Figure 3.5a) is the site S-7 representative model developed from previous studies matching moisture content/infiltration rate, propagation of barometric pressure variations, and laboratory core-sample analysis (LBNL, 1998c). The model contains continuous layers, based on the lithologies observed in VZMS-A and B. This model does not reproduce present-day TCE concentrations based on a 30-year simulation (Figure 3.3), but there are so many uncertainties involved in our assumptions about the history of site S-7 that we cannot eliminate this model from consideration. It is the simplest of the three conceptual models, and the only one that can be directly developed from the essentially one-dimensional information provided by the vertical VZMS-A and B wells. 


\section{Dual-Continua Model}

Th dual-continuum model (Figure 3.5b) considers the subsurface to be composed of two interacting continua, one consisting of preferential flow paths (PFPs) and the other of isolated sediment blocks (ISBs). The preferential flow paths are sparse, so they are rarely intersected by boreholes. However, the bulk of the liquid infiltration into the subsurface occurs through them, and they provide the network of flow paths whose permeability controls the subsurface pneumatic response to barometric pressure variations. The isolated sediment blocks comprise the bulk of the medium, so moisture contents measured with neutron probes, matric potentials measured with tensiometers, and core-sample analyses are all likely to be representative of the ISB continuum.

We assume that the intrinsic permeability of the ISBs is about 100 times smaller than that of the PFPs, and that the characteristic curves (relative permeability and capillary pressure functions) of the two continua are the same. The latter assumption is made due to lack of data on characteristic curves for hypothetical PFPs. Thus, the infiltration rate through the ISBs can be 100 times smaller than that through the PFPs while maintaining the same moisture distribution.

We hypothesize that originally the NAPL source was introduced into the subsurface via the PFPs, but that near the surface (near the NAPL source), the sediment blocks became contaminated as well. Because the PFPs carry nearly all of the infiltrating liquid through the subsurface, VOC there will show an advective depth profile whereas VOC in the sediment blocks will be transported primarily by diffusion. Because in this conceptual model the PFPs are sparse, we would not tend to sample them in the VZMS wells, hence we would only observe the diffusive VOC profile illustrated by the shallow portion of Figure 3.1a. For this model to work, we would have to assume that at depth the sediment blocks are slow to take up VOC from the neighboring PFPs. Either there has not been a long enough time to transfer significant VOC from PFPs to the sediment blocks, or there is not enough effective area of contact to allow significant interaction between PFPs and sediment blocks. This would account for the low concentrations observed in the middle depths of Figure 3.1a. The increase in concentration above the water table probably represents vestiges of a shallower water table. Beneath the water table, interactions between PFP and sediment blocks would be greatly enhanced, enabling dispersal of VOC throughout the two continua.

This dual-continua model introduces a great deal more complexity to the system relative to the single-continuum model, none of which can be directly supported by field observations. 
We introduce it for two reasons. First, the simpler single-continuum model seems inadequate to model the observed VOC concentration data, and second, the last decade of research has shown that, with a few exceptions (e.g., Wierenga, 1991; Hills et al., 1991), preferential flow is pervasive in the vadose zone (Kung, 1990a,b; Ghodrati and Jury, 1990; 1992; Li and Ghodrati, 1994; Flury et al., 1994, 1995; McCord et al., 1997).

A key unknown parameter of the dual-continua model is the strength of the interaction between the PFPs and the sediment blocks. If this interaction is strong, the two continua will essentially be in equilibrium, and show the same advective concentration profile, a feature not observed in the VZMS data. Hence, we must justify why the interaction between the two continua is limited. Merely decreasing the permeability of the ISBs does not work, because the interaction can be accomplished by gas-phase diffusion, which does not depend on permeability. Increasing the liquid saturation of the ISBs would decrease diffusion, but it would be inconsistent with the notion that the neutron probe mainly measures the ISB moisture content, so it is not a variable we are free to modify. From a geometric point of view, we expect that the interaction area between PFPs and sediment blocks will decrease with depth, as multiple PFPs coalesce to form fewer, larger PFPs (e.g., Kung, 1990a,b). Interaction area may also be temporally limited. Despite our modeling assumption of a steady infiltration rate, we believe that infiltration at McClellan AFB is episodic, with the bulk of the infiltration occurring during and after intense winter storms. If preferential flow paths are only water-filled for a small percentage of the time, then they are only likely to advect VOC-contaminated water an even smaller percentage of the time (with clean water being flushed through the system behind it). Hence, through the effects of both spatial and temporal isolation, the opportunity for PFPs to transfer VOC to the sediment blocks may be limited.

Another possible means to decrease transport of VOC from PFPs to sediment blocks is to simply make the PFPs such a small volume faction of the medium that whatever VOC they contain makes a negligible contribution to the surrounding sediment block. The limiting factor in this approach is that if the volume fraction of the PFP continuum decreases too much, the permeability required for individual flow paths would have to become unreasonably large and the transit time from the surface to the water table would become unreasonably small. Thus, there are heuristic constraints on how we divide the system into PFPs and ISBs.

\section{Anisotropic single continuum}

This conceptual model (Figure 3.5c) assumes the plume is migrating by liquid advection downward and laterally at the same time, and the VZMS holes are intersecting only the top 
portions of the plume. This migration pattern could arise from fluvial deposits and permeability differences leading to an anisotropic medium. Recharge is flowing through the entire column intersected by the VZMS holes, but below the top 25 feet or so, it is clean water that originated at the surface beyond the lateral extent of the TCE plume that intersects the VZMS-A and B wells. The low TCE concentrations arise by diffusive transport from the main plume itself, which is some distance away. While the increase in concentration near the water table is probably caused by contamination from a time when the water table was higher, it could also be due to a change of direction of the vadose zone plume that brings it closer to the monitoring location under site S-7.

This anisotropic flow conceptual model is not amenable to a one-dimensional column model or an axisymmetric $(r, z)$ model. It requires at least a two-dimensional cross-section model or preferably a fully three-dimensional model, neither of which can be developed in sufficient detail using the limited subsurface lithologic data available at this time. An estimate of the lateral distance the plume would have to travel to produce the concentration profile shown in Figure 3.1a is difficult to obtain with any certainty. A rough estimate of diffusion length is given by $(4 \alpha t)^{1 / 2}$, where diffusivity $\alpha=D_{0} S_{\mathrm{g}} \phi \tau, D_{0}=2 \times 10^{-5} \mathrm{~m}^{2} \mathrm{~s}^{-1}$ is molecular diffusivity, $S_{g}$ is gas saturation, $\phi$ is porosity, and $\tau$ is tortuosity, a function of $S_{\mathrm{g}}$ and $\phi$, which we take to be $\tau=$ $\left(\phi S_{\mathrm{g}}\right)^{2.333} / \phi^{2}$. Assuming 20-30 years for diffusion to occur, if liquid saturations are locally high (say, $S_{\mathrm{g}}=0.05$ ), $\alpha$ could be small enough to allow the plume to be only a few meters away, but if we assume $S_{\mathrm{g}}=0.3$ (consistent with the average liquid saturation of 0.7 suggested by neutron probe measurements), then a 15-20 m separation distance is more likely. The $(r, z)$ grid used for the preliminary scoping calculations is too coarse to provide reliable estimates of lateral plume spreading, but it indicates that gas-phase TCE concentration decreases from 100 ppmv to 1 ppmv over a distance of about $35 \mathrm{~m}$ after 30 years.

\section{EVALUATION AND DISCUSSION OF CONCEPTUAL MODELS}

\subsection{Two-Year Simulations}

The two years of data collected by the VZMS at Site S-7 have been used to test the first two conceptual models (the anisotropic conceptual model requires a more elaborate multidimensional numerical model, which has not been constructed). T2VOC simulations start in the spring of 1997 by applying the observed VZMS-A and B gas-phase TCE concentrations as 
initial conditions, and simulate TCE evolution until the spring of 1999. This sort of simulation has far fewer uncertainties than does a 30-year simulation, because we have a much better idea of the initial conditions. Furthermore, for a short-term simulation of a mature plume such as this, we can use a one-dimensional column model, because radial dilution will not be a major factor in plume evolution. The top and bottom boundary conditions are the same as for the $(r, z)$ model.

Our first simulation assumes that the observed gas-phase TCE concentrations represent an equilibrium between gas-phase and aqueous-phase TCE, and that there is no NAPL present. To assign grid block initial conditions, we linearly interpolate between observed TCE concentrations. The shallowest monitoring depth is 6 feet, and three options were considered for extrapolating the observed concentrations from there to the ground surface: 1) decrease concentrations from the 6 -foot value to zero at the ground surface, 2) hold concentration constant at the 6-foot value all the way to the ground surface, and 3) extend the sharp concentration gradient observed between depths of 6 and 25 feet to the ground surface. An initial simulation using option 2 produced steadily decreasing concentratons at a depth of 6 feet, in disagreement with the observed concentration there, which increases with time (Figure 3.1b). Next, we tried a two-year simulation using option 3 , the reasoning being that the increasing concentrations seen at 6 feet originate at shallower depths. Figure 4.1 shows the resulting simulated concentrationdepth profiles after 0, 1, and 2 years (i.e., the springs of 1997, 1998, and 1999), and Figure 4.2 shows simulated concentrations as a function of time for depths of $3,6,11,18$, and 30 feet. Note that TCE concentration at a depth of 3 feet decreases rapidly, due to losses to the atmosphere, and that concentration at 6 feet increases just slightly before decreasing. At depths greater than 6 feet, both observed and model concentrations increase gradually with time. Apparently, even when we use option 3 and start with rather high concentrations near the surface, losses to the atmosphere preclude a significant concentration increase at a depth of 6 feet.

We tried to improve the model by decreasing gas-phase diffusion to the atmosphere, by assuming a stronger capillary pressure for the shallow concrete layer, resulting in a larger liquid saturation at that depth (which is shallower than any of the moisture content observations). The modified model does show TCE concentrations at the 6-foot depth that increase with time, but the propagation of barometric pressure variations into the subsurface no longer agrees with observed data, so this model modification must be rejected. Next, we tried adding temporal variations in surface temperature, atmospheric pressure, and infiltration rate, but none of these features helped the model match the shallow concentration data. Therefore, we hypothesize that either some NAPL remains in the system, gradually volatalizing to replace gas-phase TCE that is 
lost to the atmosphere, or that TCE-contaminated water flows through the gravel layer between the two concrete layers in the shallowest 3 feet of the system and acts to replenish the TCE source. If NAPL is present, it must be a small amount, somewhat isolated from any monitoring location, otherwise the observed TCE gas-phase concentrations would be much higher. It is probably located shallower--although we cannot say how much shallower--than the uppermost monitoring location at a depth of 6 feet, because of the monotonic decrease of the concentrationdepth profile between 6 and 25 feet and the increasing concentration-time trends at these depths. Constraints on the VOC-contaminated lateral water flow possibility are minimal, and thus we focus on testing the NAPL hypothesis.

To test the NAPL hypothesis, we added a small grid block containing about 10 grams of TCE with a NAPL saturation of 0.7 at a depth of 3 feet, and reran the two-year simulation. Figure 4.3 shows the resulting TCE concentration-depth profiles, and Figure 4.4 shows the corresponding concentration transients for several depths. The model now shows a gradual increase in TCE concentration at all depths, corresponding to a small downward movement of the TCE plume. This downward movement results from a combination of advection and diffusion. We can estimate the advection contribution by converting the percolation rate of $100 \mathrm{~mm} / \mathrm{yr}$ to a pore velocity by dividing by average porosity (0.47) and liquid saturation (0.7). This yields a pore velocity of $0.3 \mathrm{~m} / \mathrm{yr}$ and a corresponding water travel time from the ground surface to the water table of 112 years for the single-continuum model. Hence in a two-year simulation period, the TCE plume would be advected less than 2 feet. Given the spacing and variability in the observed TCE data, the single-continuum model is consistent with the observed data, for this short time period.

We repeated the two-year simulation with a small NAPL source for two versions of the dual-continua model. T2VOC contains an automated grid-generator called MINC (Multiple Interacting Continua) that converts a single-continuum grid into a dual-continua grid (Pruess, 1991). The user specifies the volume fraction of each continuum, several geometric parameters that control the interaction between continua (including the characteristic length scale and geometric structure of PFPs), and the material properties of each continuum. In the first case, we assume that the PFPs make up 5\% of the subsurface volume, but in the second case only $0.2 \%$. These percentages are not based on hard data, but are intended to represent a range of possible configurations. In the first case, the water travel time from the surface to the water table is 6 years, whereas in the second case it is only 3 months. In both cases, we assume typical PFP spacing is $2 \mathrm{~m}$, and the PFPs have a ribbon-like structure (as opposed to a planer structure that might be used to represent a fractured medium). As mentioned in Section 3, material properties 
for the two continua are identical, with the exception that the intrinsic permeability of the ISBs is 100 times lower than that of the PFPs, resulting in initial conditions for the two-year simulation consisting of identical moisture distributions in the two continua, with 100 times less infiltration in the ISBs.

For the $5 \%$ PFP case, there is a strong interaction between PFPs and ISBs, and both show similar concentration profiles that do not differ greatly from those of the single-continuum model. For the $0.2 \%$ case, the situation is noticeably different, as illustrated in Figure 4.5, which shows the concentration-depth profiles for the two continua. For the PFPs there is a significant advective contribution, whereas for the ISBs the concentration profile is diffusion controlled. The ISB concentration profile affects the PFP profile, increasing shallow concentrations, but because the PFP volume fraction is so small, it does not significantly affect the ISB profile. Recall that for our present conceptual model, the ISB concentrations are the ones to be compared to field data. Figure 4.6 shows the concentration transients. Those representing the ISBs are reasonably consistent with the observed data.

Our preliminary conclusion from the two-year simulations is that we cannot eliminate either of the first two conceptual models from further consideration. The single-continuum model actually matches the concentration transients a little bit better, but this may not be attributable to the strength of advection. Instead, subtle differences in the details of the liquid saturation profile between the model and the actual system can lead to differences in gas-phase diffusion that lead to a good match. In the paragraphs below, we briefly describe the results of three additional simulations using the single-continuum model, designed to incorporate more realism into the models by looking at temporal variations in the surface temperature, atmospheric pressure, and infiltration rate applied to the model. In each case, the initial condition with a small NAPL source at 3 feet and a gas-phase TCE profile interpolated and extrapolated from the spring 1997 observed values is used. Future studies will examine the effect of these surface variations on a dual-continua model.

Figure 4.7 shows TCE concentration versus time for a two-year simulation when the sinusoidally varying surface temperature shown by the analytical solution in Figure 2.4 is applied to the top boundary of the model. Soil gas TCE concentrations vary noticeably with subsurface temperature, as TCE is preferentially partitioned into the gas phase at higher temperatures. As temperature changes decrease with depth (see Figure 2.5), so do concentration changes. As mentioned in Section 2, temperature effects tend to average out over time, and snapshots of the 
TCE plume after 1 or 2 years of simulation look very similar to those obtained with a constant surface temperature.

Figure 4.8 shows the atmospheric pressure variation with time during 1997-1999, as measured at Site S-7. This pressure record was applied to the top boundary of the model for a two-year simulation, and Figure 4.9 shows the resulting TCE concentration versus time. Shortterm oscillations in concentration are visible at a depth of 3 feet, but below that atmospheric pressure effects are more gradual. The concentration at 6 feet decreases more and the concentration at 11 feet increases more than in the constant-pressure case (Figure 4.4), as the TCE plume is pushed slightly deeper by an increasing atmospheric pressure.

Figure 4.10 shows the daily precipitation record at McClellan AFB (CDEC, 1999). For the model, we take the monthly average precipitation values, and assume infiltration is $20 \%$ of precipitation. Figure 4.11 shows TCE concentration versus time when such a variable infiltration rate is applied. Direct evidence of the variable infiltration rate only appears at a depth of 3 feet, where concentration varies in response to short-term changes in infiltration rate. At 6 and 11 feet, the concentration transient differs slightly from the constant-infiltration case (Figure 4.4), suggesting that the TCE plume is pushed slightly deeper when infiltration rate varies.

\subsection{Estimates of VOC Flux}

Because the present models are so preliminary, the following estimates of VOC flux should be considered very rough. Table 4.1 shows the mass fluxes of TCE in the aqueous and gas phases for the single-continuum and dual-continua models at the end of the two-year simulations (i.e., at the present day). The maximum aqueous and downward gas fluxes occur shallow in the vadose zone, at and just below the TCE concentration maximum. The differences between the two conceptual models are significant, and indicate that further investigation into the best conceptual model for the McClellan site is warranted. 
Table 4.1. TCE fluxes in $\mathrm{kg} \mathrm{m}^{-2} \mathrm{yr}^{-1}$ calculated by T2VOC at the end of the two-year simulations.

\begin{tabular}{|c|l|l|l|l|}
\hline & $\begin{array}{l}\text { Maximum } \\
\text { Aqueous flux }\end{array}$ & $\begin{array}{l}\text { Aqueous Flux at } \\
\text { Water Table }\end{array}$ & $\begin{array}{l}\text { Gas Flux to } \\
\text { Atmosphere }\end{array}$ & $\begin{array}{l}\text { Maximum Downward } \\
\text { Gas Flux }\end{array}$ \\
\hline \hline $\begin{array}{l}\text { Single-Continuum } \\
\text { Model }\end{array}$ & $9 \times 10^{-5}$ & $5 \times 10^{-6}$ & $2 \times 10^{-4}$ & $4 \times 10^{-5}$ \\
\hline $\begin{array}{l}\text { Dual-Continua } \\
\text { Model }\end{array}$ & & & & \\
PFPs & $3 \times 10^{-6}$ & $2 \times 10^{-6}$ & $\begin{array}{l}3 \times 10^{-5} \\
6 \times 10^{-4}\end{array}$ & $\begin{array}{l}2 \times 10^{-6} \\
2 \times 10^{-5}\end{array}$ \\
\hline ISBs & $1 \times 10^{-6}$ & $4 \times 10^{-8}$ & & \\
\hline
\end{tabular}

\subsection{Limitations and Caveats}

The present one-dimensional models provide highly simplified representations of the subsurface flow and transport of VOC, and numerous assumptions have been made for the twoyear simulations. Any results shown at this point must be viewed as tentative. In particular, the assumptions made for the dual-continua model are not well constrained by observed data. Furthermore, some processes, such as the chemical transformation of TCE to cis-1,2-DCE and non-equilibrium effects have not been considered at all.

\section{DISCUSSION OF PRIOR VAPOURT RESULTS}

\subsection{Introduction}

After two years of data collection with the VZMS installed in S-7, we are in a position to discuss the prior VapourT modeling results carried out for the S-7 site as reported in Jacobs (1998). Because VZMS data represent conditions in particular boreholes at S-7, whereas VapourT predictions are generalized for the S-7 site as a whole, the discussion and evaluation of VapourT predictions will be based on a combination of VZMS data and more generalized enhanced data analysis results as presented in Sections 3 and 4 of this report. 


\subsection{Prior VapourT Modeling}

Model analyses of cis-1,2-DCE transport using VapourT (Mendoza and Frind, 1990a,b; Mendoza, 1992) have been carried out by Jacobs Engineering (Jacobs, 1998) for the S-7 site. VapourT was chosen because of its capabilities for modeling VOC transport by diffusion, dispersion, and advection in gas and aqueous phases, density-driven gas-phase flow, as well as VOC gas-aqueous phase partitioning including adsorption. VapourT simulation results can be used to predict the potential for VOCs to migrate from the vadose zone to the water table and to escape to the atmosphere through the ground surface. VapourT predictions, along with associated sensitivity analyses, can be used as a basis for decisions on remediation.

The appropriateness of VapourT modeling is established for vadose zone sites where the temperature is between $20-25^{\circ} \mathrm{C}$, where NAPL migration is negligible over the timeframe of the simulation, and where adequate characterization of VOC concentrations and subsurface geology has been carried out (Jacobs, 1998). Procedures for VapourT modeling at McClellan AFB are set out formally in Jacobs (1998, App. B). These procedures involve the identification of the center of mass of the VOC, as well as delineation of a vertical profile of VOC concentrations through the vadose zone. Because of the sparseness of VOC contaminant concentration data, as well as its heterogeneity in both the horizontal and vertical directions, interpolation and extrapolation procedures for defining the initial VOC contaminant distribution based on limited concentration data are defined (Jacobs, 1998, pp. B19-B25).

Using lithologic data from several boreholes in S-7, and contaminant concentration data from borehole SS7SB08 (see Figure 1.1) consistent with the VapourT modeling procedures, a layered geologic model and an initial profile of cis-1,2-DCE were established by Jacobs (1998). The initial condition has cis-1,2-DCE in the gas phase at 170 ppmv at a depth of 22 feet decreasing to $33 \mathrm{ppmv}$ at 52 feet. Using a generalized lithology consisting of sand layers and a silt layer with permeabilities ranging from $1.3 \times 10^{-10} \mathrm{~m}^{2}-1.0 \times 10^{-12} \mathrm{~m}^{2}$, porosity ranging from $0.47-0.49$, moisture content ranging from $0.10-0.24$, and fraction organic carbon $0.00035-$ 0.00087 , a two-dimensional radial model grid was constructed. VapourT model results predicted leachate concentrations would increase from 1 to $4.4 \mathrm{mg} \mathrm{L}^{-1}$ within 70 to 75 years. Meanwhile the atmospheric losses would decrease with time from $2.9 \times 10^{-9} \mathrm{~kg} \mathrm{~m}^{-2} \mathrm{hr}^{-1}$ in 5 years, to $1.2 \mathrm{x}$ $10^{-9} \mathrm{~kg} \mathrm{~m}^{-2} \mathrm{hr}^{-1}$ in 100 years.

The processes active in the VapourT simulation are gas phase diffusion, dispersion, and advection, water advection downward at a constant percolation rate of $2.0 \times 10^{-9} \mathrm{~m} \mathrm{~s}^{-1}$, and 
partitioning of the VOC between gas, aqueous, and solid phases. In this layered conceptualization, cis-1,2-DCE partitions into the infiltrating water and is transported downward by Darcy flow through the single-continuum porous medium toward the water table. With percolation rate of $2.0 \times 10^{-9} \mathrm{~m} \mathrm{~s}^{-1}$, average porosity of 0.48 , and moisture content of 0.17 , the pore velocity is $1.2 \times 10^{-8} \mathrm{~m} \mathrm{~s}^{-1}$, or approximately $0.4 \mathrm{~m} \mathrm{yr}^{-1}$. This downward flow is augmented by diffusion, dispersion, and density-driven gas-phase flow, all of which lead to the predictions of increasing leachate and groundwater concentrations and decreasing atmospheric fluxes over the next century or so.

\subsection{Discussion and Comparison to VZMS Results}

There are two important aspects to any model application: (1) the model itself along with its mathematical formulations of physical processes and related approximations; and (2) the procedures used to implement the model at any given site. In this section, we discuss these two aspects for VapourT applications at S-7, and then turn to comparisons with VZMS data and our own T2VOC transport simulations.

In order to be widely applicable, the VapourT model is based on several assumptions that are thought to be generally appropriate to vadose zone VOC transport scenarios. In the passive migration mode, the VapourT model solves for VOC transport in a vadose zone with constant (steady-state) recharge, as well as constant moisture content in each layer. It is assumed that there is no NAPL movement. The depth to the water table (vadose zone thickness) is assumed constant throughout the simulation. A constant atmospheric pressure boundary condition at the top of the domain is assumed (i.e., no barometric pumping effects), along with isothermal conditions throughout. Degradation of the VOC through biological or chemical transformation is not modeled. Local equilibrium is assumed for the partitioning of VOC between the gas, aqueous, and solid (e.g., organic carbon) phases. Implicit in VapourT is the flow of gas and aqueous phases through a single permeable medium, with no account made for preferential or fracture flow effects through the dual-continua approximation.

VapourT has been used at S-7 under the procedures laid out by Jacobs (1998). The procedures involving delineation of through-going layers and interpolation of contaminant concentrations appear reasonable, especially given the challenge of carrying out generalized modeling for heterogeneous sites with sparse data. The choice of an axisymmetric grid for the S-7 site is consistent with the accepted understanding of the source area. The value of the constant 
percolation rate $\left(2.0 \times 10^{-9} \mathrm{~m} \mathrm{~s}^{-1}\right)$ is also reasonable, given that the relevant simulation times are on the order of decades. It appears that the procedures used to implement VapourT at S-7 are appropriate for making generalized predictions from the VapourT model.

Despite the apparent reasonableness of the VapourT applications at S-7, the data on VOC contaminant distributions collected by the VZMS do not substantiate VapourT predictions. As shown in Figures 3.1a and 3.2a and discussed in Sections 3 and 4, both TCE and cis-1,2-DCE profiles show high concentrations in the shallow vadose zone, and very low concentrations at depths greater than 20 feet. VapourT predictions using the constant $2.0 \times 10^{-9}$ $\mathrm{m} \mathrm{s}^{-1}$ percolation rate lead to downward VOC advection at rates that would bring large concentrations of VOC to a depth of $12 \mathrm{~m}$ (40 feet) after 30 years, a feature not observed in VZMS data. Our T2VOC simulations for a simple single continuum conceptualization discussed in Sections 3 and 4 are similar to the VapourT simulations, and show VOC profiles that are not consistent with VZMS data. The discussion of Section 4 on possible reasons for discrepancies between VZMS data and T2VOC simulations is applicable here. In addition, the VapourT predictions are based on the cis-1,2-DCE profile from borehole SS7SB08 for the initial condition. Borehole SS7SB08 shows high cis-1,2-DCE contamination at a depth of $8 \mathrm{~m}$ (Jacobs, 1998; Figure 3.1), a feature not observed in the nearby VZMS wells. If the preferential flow path conceptualization discussed in Section 3 is applicable to the S-7 site, then VapourT predictions underpredict the velocity of VOC from the shallow source to the water table. However, with this same conceptualization, the total mass transported to the water table will be overpredicted by VapourT, since very little VOC will be advected through the preferential flow paths and the large storage and slow transport through the isolated sediment blocks are not considered in the single-continuum VapourT model.

In summary, model predictions that use simple conceptualizations of VOC transport cannot be substantiated by comparison to VZMS data. In particular, the VapourT results for the S-7 site using initial conditions from well SS7SB08 as presented by Jacobs (1998) are not consistent with the site S-7 VZMS data. However, as our discussion in Sections 3 and 4 emphasizes, matching VZMS VOC concentration data with numerical simulation results is challenging and may require detailed consideration of preferential flow paths through multiple interacting continuum approaches, and two- and three-dimensional aspects of the underlying hydrostratigraphic layers, in particular heterogeneity in permeability and porosity including discrete flow paths. We have endeavored to use the VZMS data to constrain and develop conceptualizations consistent with these data (see Sections 3 and 4). But the VZMS data represent conditions in the immediate vicinity of the boreholes and may not be representative of 
the S-7 site in general. Without further data from the S-7 site, we conclude only that VOC data from VZMS-A and B do not substantiate the generalized VapourT predictions of Jacobs (1998) that are based on the cis-1,2-DCE concentrations in SS7SB08.

\section{SUMMARY AND CONCLUSIONS}

We have used analytical solutions and the previously developed numerical model of Site S7 to examine heat and VOC transport, and compare model predictions to data observed in the VZMS wells. Observed temperature data agree well with a simple conduction model for heat transfer. Through this enhanced data analysis, we find that surface temperatures at the S-7 site are higher than air temperatures, and that the vadose zone recharge water is warmer than the groundwater at the water table.

Preliminary modeling results for VOC transport were not consistent with TCE and cis1,2-DCE concentrations observed in the VZMS holes. We believe that the observed data show that with the physical processes considered by $\mathrm{T} 2 \mathrm{VOC}$, and the assumptions made about the source of VOC, a layered single-continuum model is not adequate to match the evolution of VOC in the subsurface. The advective signature of such a model is not present in the VZMS data, hence a model with very limited liquid infiltration matches the data better. In order to maintain consistency with moisture content and pressure data, we must hypothesize a more complicated model in which liquid infiltration occurs, but does not advect VOC past the VZMS wells at S-7. Two possibilities include a dual-continua model, consisting of preferential flow paths and isolated matrix blocks, and an anisotropic single-continuum model. Both of the new conceptual models require additional assumptions that are not well-constrained by observed data. Because of the uncertainties involved in simulating the decadal history of a VOC plume, we attempted to use two years of VZMS data to ascertain which of the two one-dimensional conceptual models (single-continuum or dual-continua) performed better. Although we cannot eliminate either onedimensional conceptual model on the basis of this test, we can make the following observations:

- It appears likely that there are VOCs shallower than 6 feet, the shallowest VZMS monitoring location, because all shallow monitoring locations show gradual increases in TCE concentration.

- There does not appear to be an extensive NAPL body anywhere near any monitoring location, because all TCE concentrations are several orders of magnitude lower than the gasNAPL equilibrium values. 
- The lack of TCE concentration decline with time at the 6-feet depth suggests that atmospheric losses may be less than currently assumed or that there is a continuing shallow source of TCE present. This source could be small and isolated NAPL sources, or shallow lateral TCE-contaminated groundwater flow.

Based on two years of gas-phase VOC concentration data, along with our own experience modeling VOC transport at S-7, we find that prior VapourT modeling at the S-7 site cannot be substantiated. This result must not be taken out of the context in which modeling predictions are made, namely that they are generalized for the site as a whole, whereas the VZMS data are taken from specific locations that may or may not be representative of the entire site. Nevertheless, our own modeling efforts point strongly to the need for dual-continua or two- or threedimensional models with associated characterization data to accurately simulate VOC transport at S-7. The present results have focused on VZMS-A and B data. Future work will incorporate data from VZMS-C to further constrain data interpretations.

\section{ACKNOWLEDGMENTS}

We thank Stefan Finsterle and Peter Zawislanski for helpful reviews. This work was supported by the U.S. Department of Defense under Military Interdepartmental Purchase Request FD2040-96-74020EM to the Ernest Orlando Lawrence Berkeley National Laboratory, managed for the U.S. Department of Energy under contract DE-AC03-76SF00098.

\section{REFERENCES}

CDEC, 1999, California Data Exchange Center, Division of Flood Management, http://cdec.water.ca.gov/misc/DailyPrecip.html http://cdec.water.ca.gov/cgi-progs/queryDaily?SPO http://cdec.water.ca.gov/cgi-progs/queryDaily?SMF.

Falta, R. W., K. Pruess, S. Finsterle, and A. Battistelli, 1995, T2VOC user's guide, Lawrence Berkeley Laboratory Report, LBL-36400, Berkeley, California (March 1995).

Falta, R.W., and I. Javandel, K. Pruess, and P.A. Witherspoon, 1989, Density-driven flow of gas in the unsaturated zone due to the evaporation of volatile organic compounds, Water Resour. Res., 25(10), 2159-2169. 
Finsterle, S., 1997, ITOUGH2 command reference, Lawrence Berkeley National Laboratory Report, LBNL-40041, Berkeley, California, (April, 1997).

Flury, M., H. Flühler, W.A. Jury, and J. Leuenberger, 1994, Susceptibility of soils to preferential flow of water: a field study, Water Resour. Res., 30(7), 1945-1954.

Flury, M., J. Leuenberger, B. Studer, and H. Flühler, 1995, Transport of anions and herbicides in a loamy and sandy field soil, Water Resour. Res., 31(4), 823-835.

Ghodrati, M., and W.A. Jury, 1992, A field study of the effecs of soil structure and irrigation method on preferential flow of pesticides in unsaturated soil, J. Contam. Hydrology, 11, 101125.

Ghodrati, M., and W.A. Jury, 1990, A field study using dyes to characterize the preferential flow of water, Soil Sci. Soc. Am. J., 54, 1558-1563.

Hillel, D.R., 1980, Fundamentals of Soil Physics, Academic Press, New York.

Hills, R.G., P.J. Weirenga, P.J., D.B. Hudson, and M.R. Kirkland, 1991, The second Las Cruces trench experiment: experimental results and two-dimensional flow predictions, Water Resour. Res., 27(10), 2707-2718.

Jacobs Engineering, 1998, Remedial Investigation Characterization Summary for Investigation Cluster 34, Part 2A, Jacobs Engineering.

Kung, K-J.S., 1990a, Preferential flow in a sandy vadose zone: 1. Field observation, Geoderma, $46,51-58$.

Kung, K-J.S., 1990b, Preferential flow in a sandy vadose zone: 2. Mechanism and implications, Geoderma, 46, 59-71.

LBNL, 1996, Vadose zone monitoring system installation report for McClellan AFB. Prepared by Zawislanski, P.T., B. Faybishenko, A. James, B. Freifeld, and R. Salve, Report to the Department of the Air Force, McClellan AFB, Lawrence Berkeley Laboratory Report, LBNL-39525, Berkeley, California, (October, 1996).

LBNL, 1998a, Data analysis for preliminary conceptual model design, vadose zone monitoring system (VZMS), McClellan AFB. Prepared by Zawislanski, P. T. and C. M. Oldenburg, Annual Report to the Department of the Air Force, McClellan AFB, Lawrence Berkeley Laboratory Report, LBNL-41262, Berkeley, California, (January, 1998).

LBNL, 1998b, Enhanced data analysis for the VZMS: Conceptual model design and initial application for the vadose zone monitoring system (VZMS), McClellan AFB. Prepared by James, A. L. and C. M. Oldenburg, Semi-Annual Report to the Department of the Air Force, 
McClellan AFB, Lawrence Berkeley Laboratory Report, LBNL-41909, Berkeley, California, (June, 1998).

LBNL, 1998c, Representative model and application for the vadose zone monitoring system (VZMS), McClellan AFB. Prepared by James, A. L. and C. M. Oldenburg, Semi-Annual Report to the Department of the Air Force, McClellan AFB, Lawrence Berkeley Laboratory Report, LBNL-42643, Berkeley, California, (December, 1998).

LBNL, 1999, Monitoring and data analysis for the vadose zone monitoring system (VZMS), McClellan AFB. Prepared by P.T. Zawislanski, Quarterly Status Report to the Department of the Air Force, McClellan AFB, Lawrence Berkeley Laboratory Report, LBNL-43084, Berkeley, California, (April, 1999).

Li, Y., and M. Ghodrati, 1994, Preferential transport of nitrate through soil columns containing root channels, Soil Sci. Soc. Am. J., 58, 653-659.

McCord, J.T., C.A. Gotway, and S.H. Conrad, 1997, Impact of geologic heterogeneity on recharge estimation using environmental tracers: numerical modeling investigation, Water Resour. Res., 33(6), 1229-1240.

Mendoza, Carl A., 1992, VapourT version 2.11 user's guide.

Mendoza, C.A., and E.O. Frind, 1990a, Advective-dispersive transport of dense organic vapors in the unsaturated zone 1. Model development, Water Resour. Res., 26(3), 379-387.

Mendoza, C.A., and E.O. Frind, 1990b, Advective-dispersive transport of dense organic vapors in the unsaturated zone 2. Sensitivity analysis, Water Resour. Res., 26(3), 388-398.

NOAA, 1999, National Oceanic and Atmospheric Administration, National Climate Data Center (NCDC) Daily Station, http://ingrid.ldgo.columbia.edu/SOURCES/.NOAA/NCDC/.DAILY/.STATION.cuf/IWMO/ 724836/VALUES/.mean.

Pruess, K., 1991, A general-purpose numerical simulator for multiphase fluid and heat flow, Lawrence Berkeley Laboratory Report, LBL-29400, Berkeley, California.

Weirenga, P.J., R.G. Hills, and D.B. Hudson, 1991, The Las Cruces trench site: characterization, experimental results, and one-dimensional flow predictions, Water Resour. Res., 27(10), 2695-2705. 


\section{FIGURES}



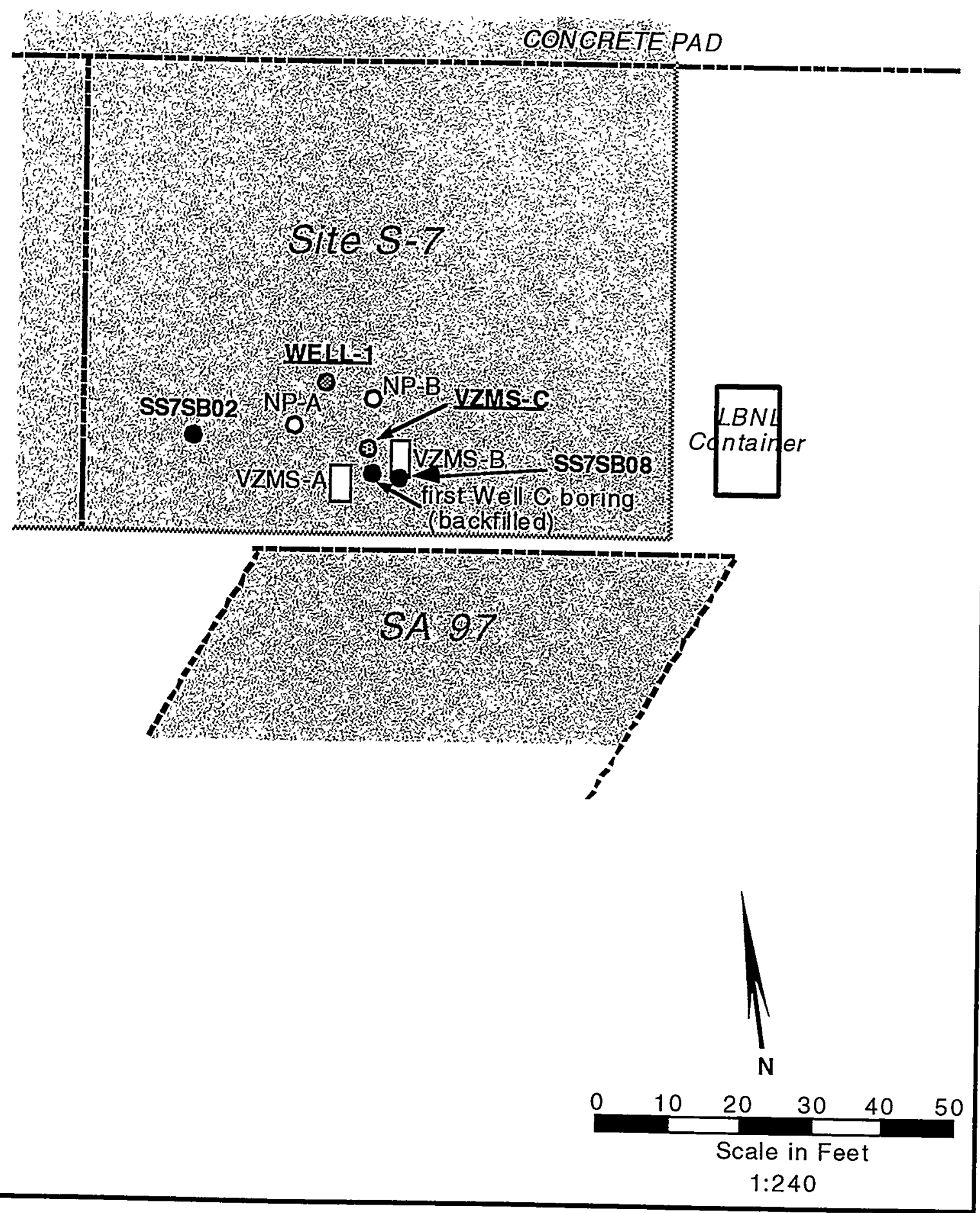

Figure 1.1. Map of site S-7. 


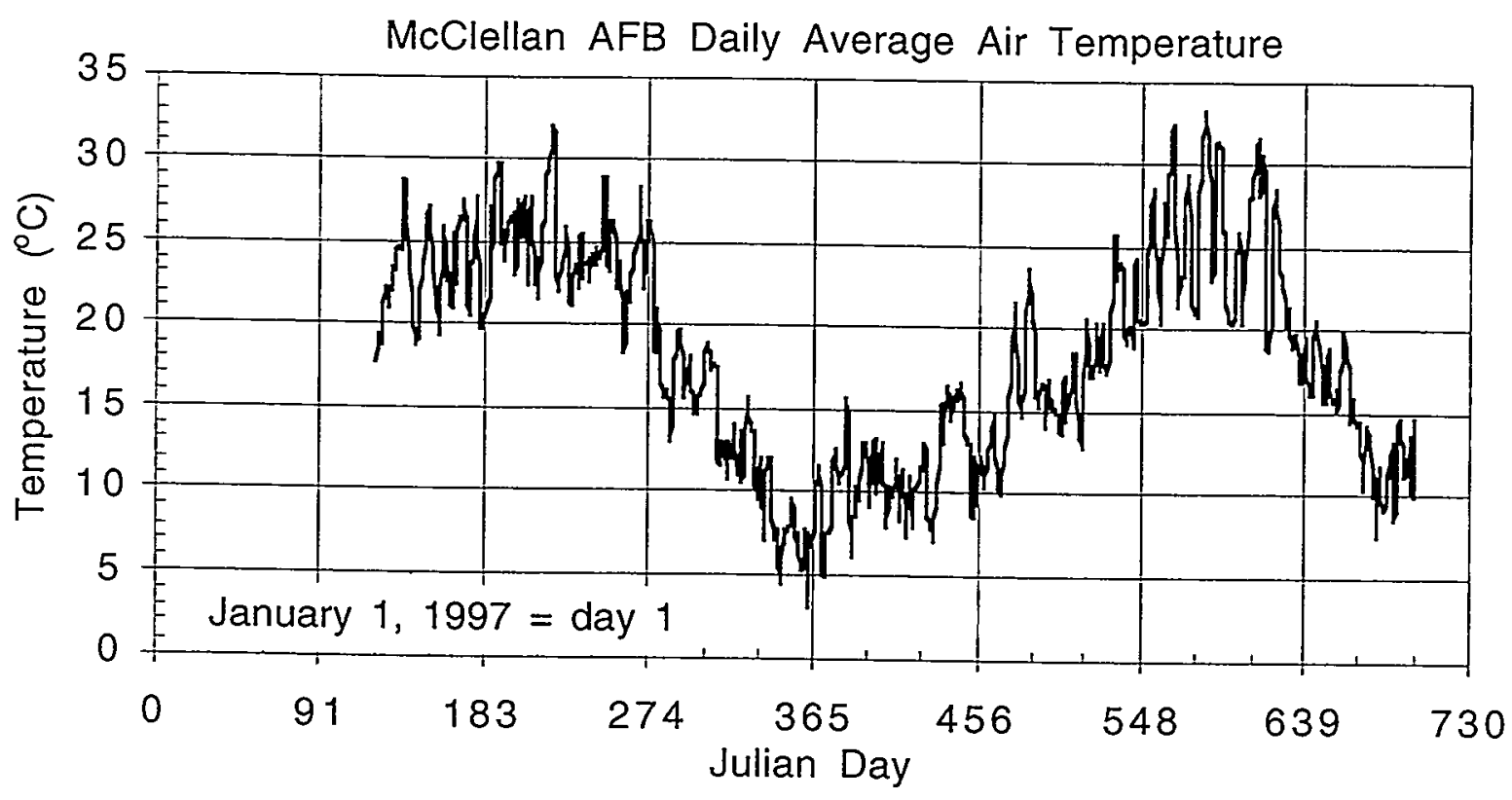

Figure 2.1. Daily average air temperature at McClellan AFB from May 1997 through December 1998.

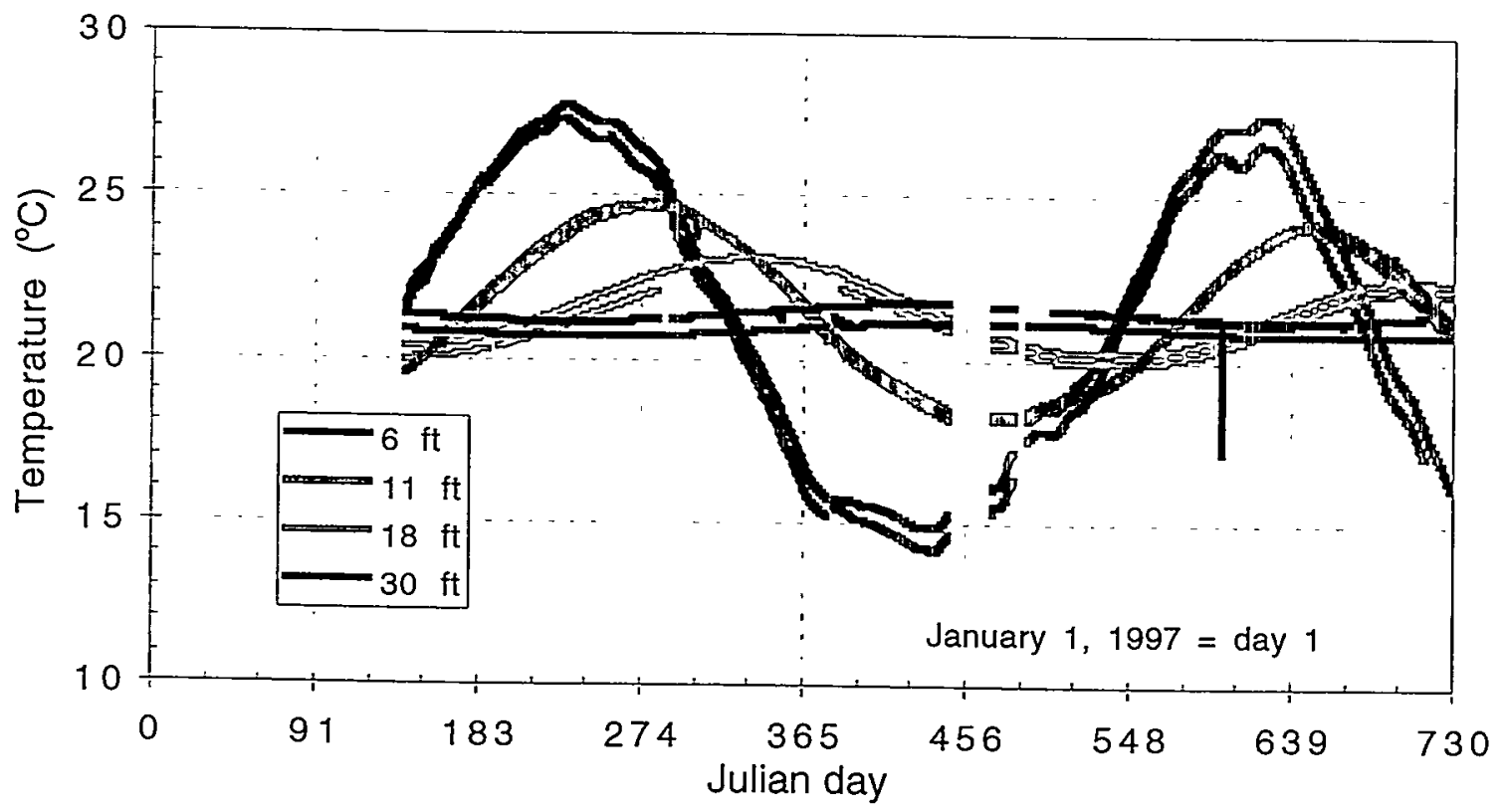

Figure 2.2. Subsurface temperatures measured in Wells VZMS-A and VZMS-B from May 1997 through December 1998. 


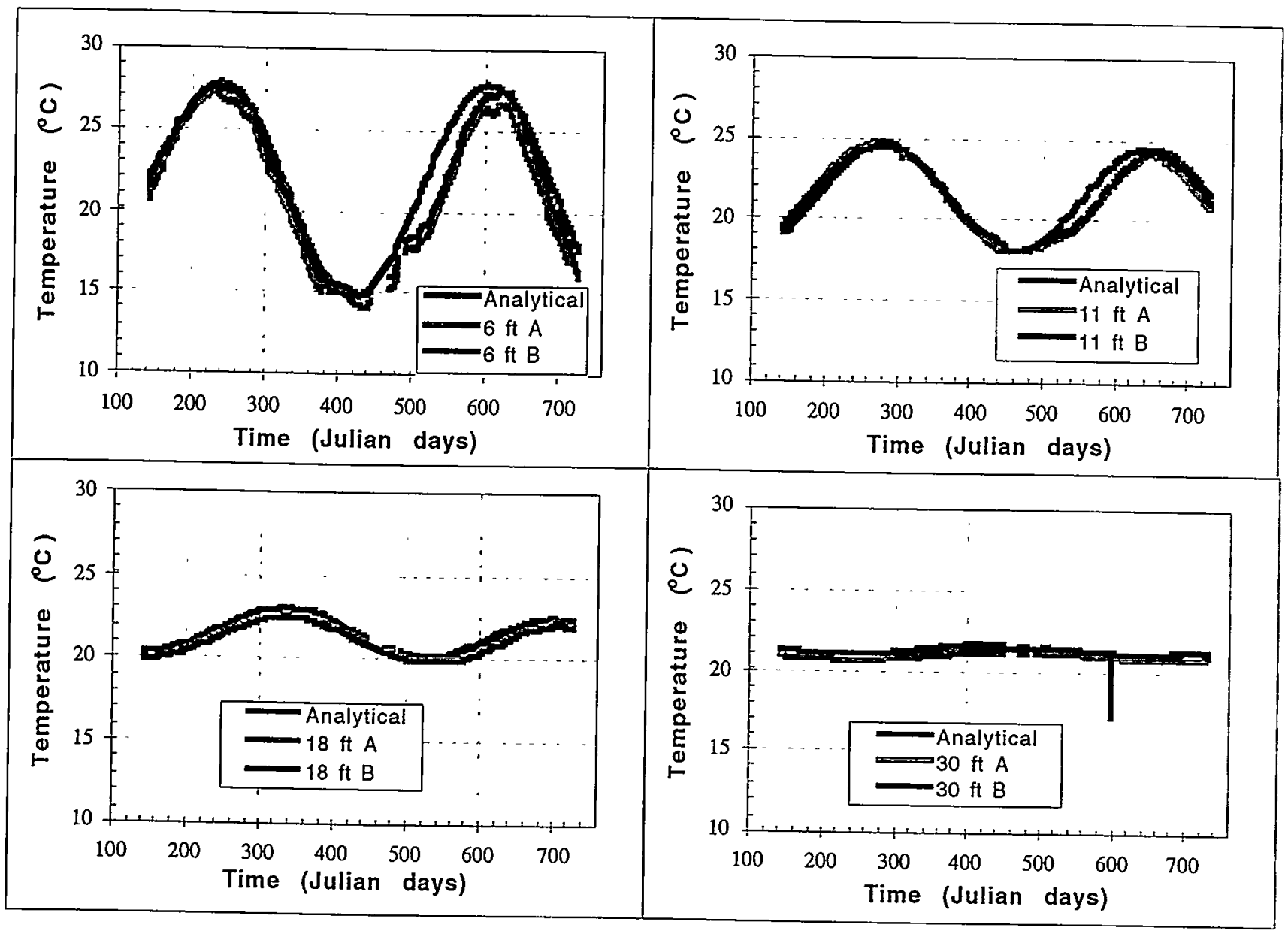

Figure 2.3. Comparison of observed subsurface temperatures with analytical solution for conductive heat transfer. 


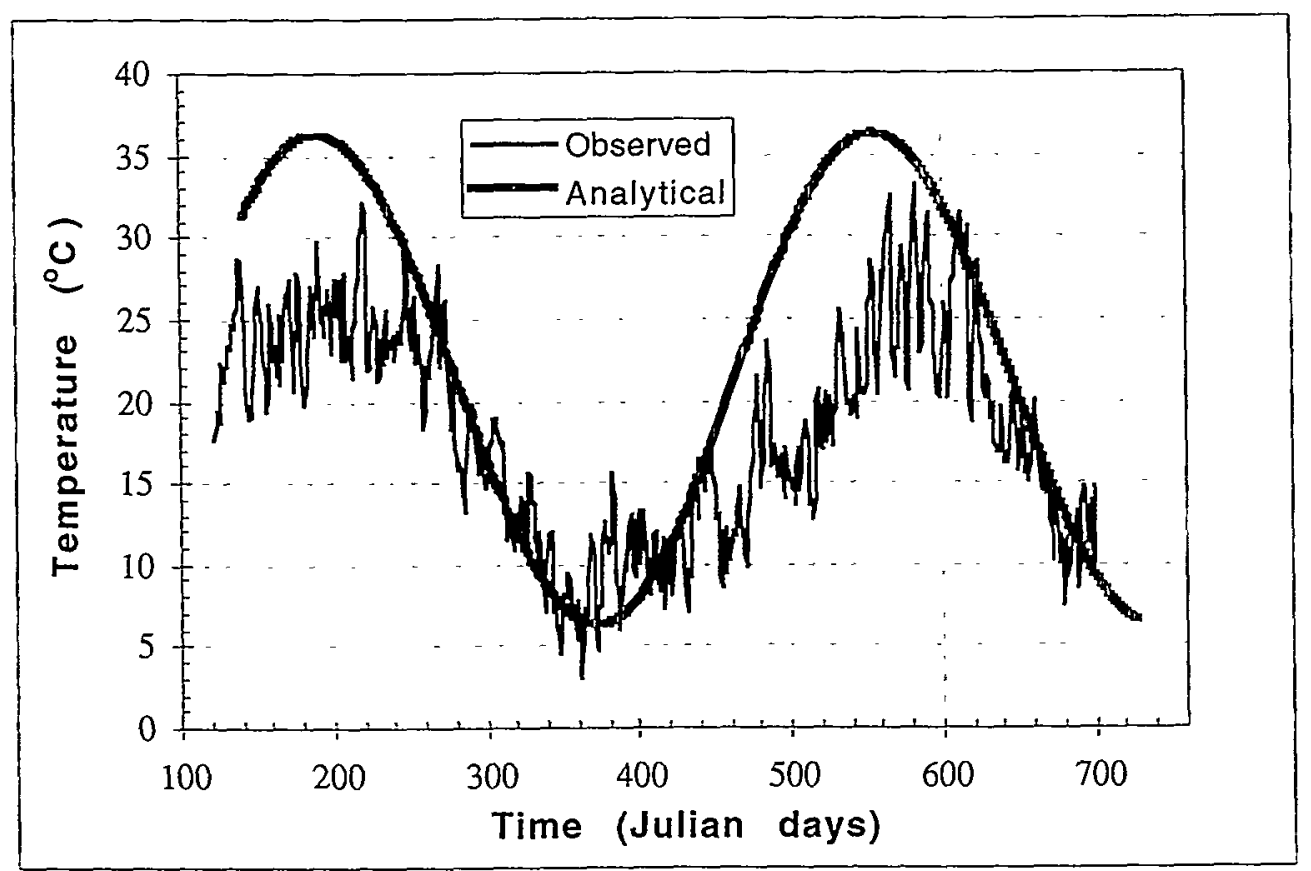

Figure 2.4. Comparison of observed air temperature with sinusoidal ground surface temperature obtained by fitting analytical solution to subsurface temperatures, as shown in Figure 2.3. 


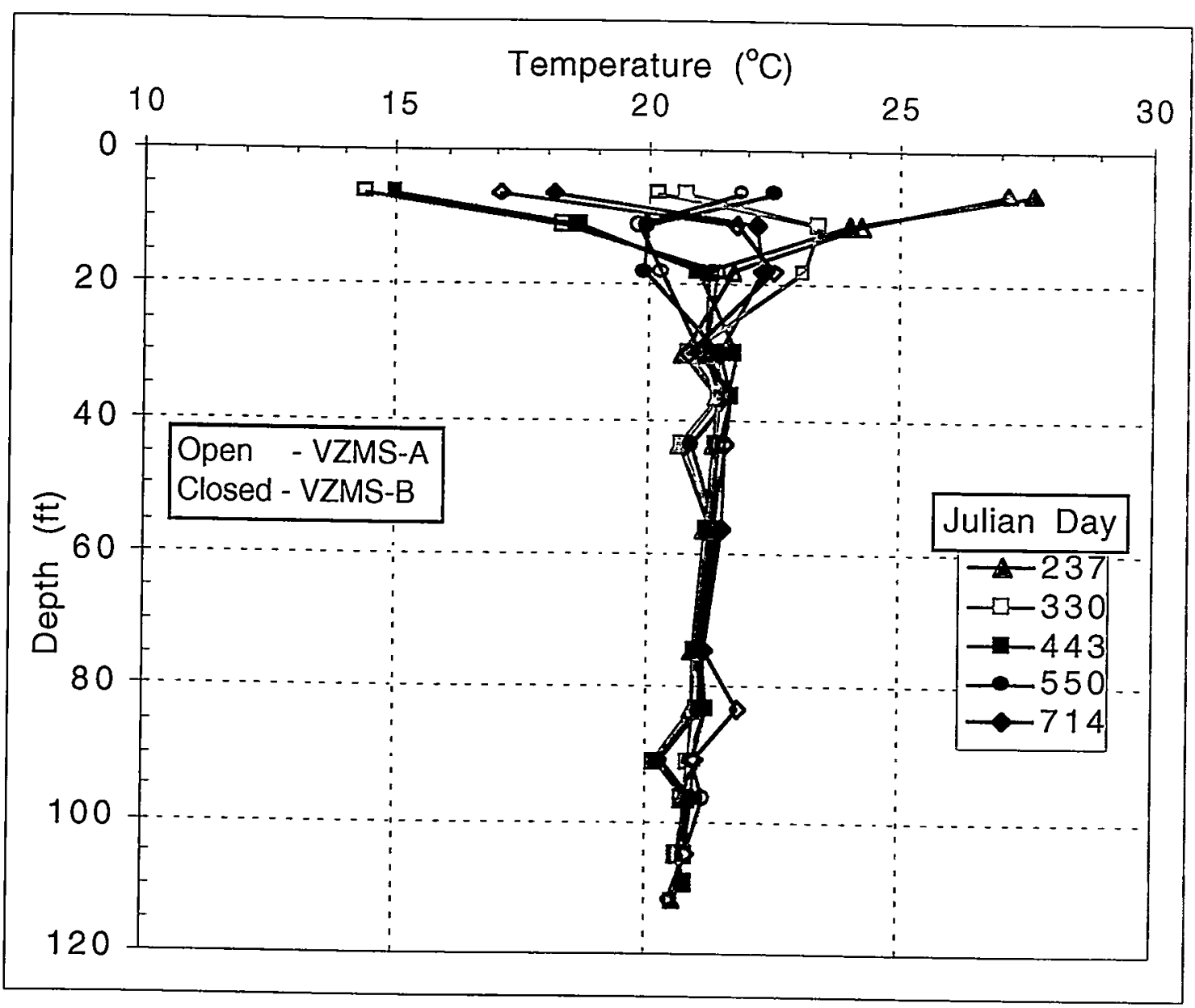

Figure 2.5. Temperature versus depth profiles for several times. (Open symbols show VZMSA, closed symbols VZMS-B). 
(a)

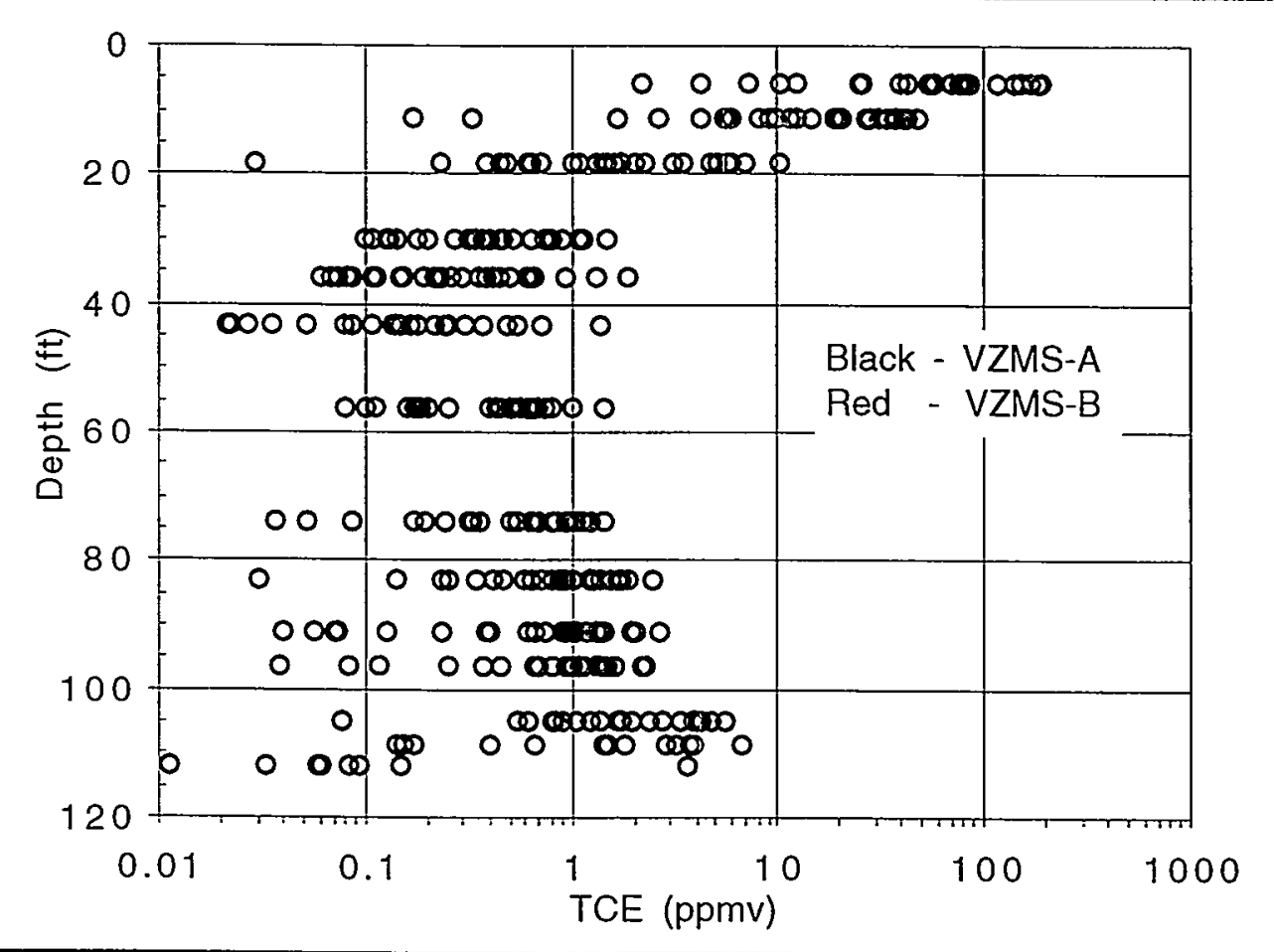

(b)

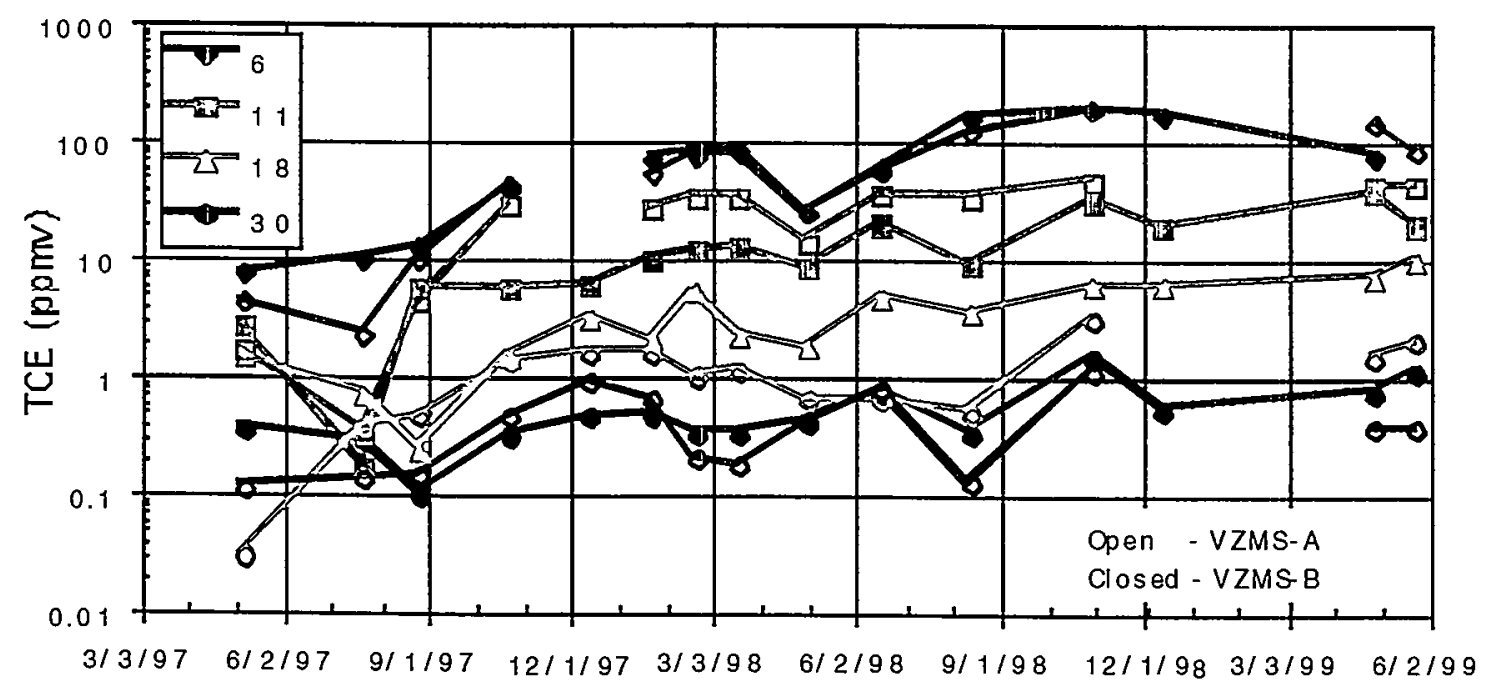

Figure 3.1. (a) Gas-phase TCE concentration-depth profiles observed in Wells VZMS-A and VZMS-B at a series of times between May 1997 and May 1999; (b) Gas-phase TCE concentrations as a function of time for shallow observation depths. 
(a)

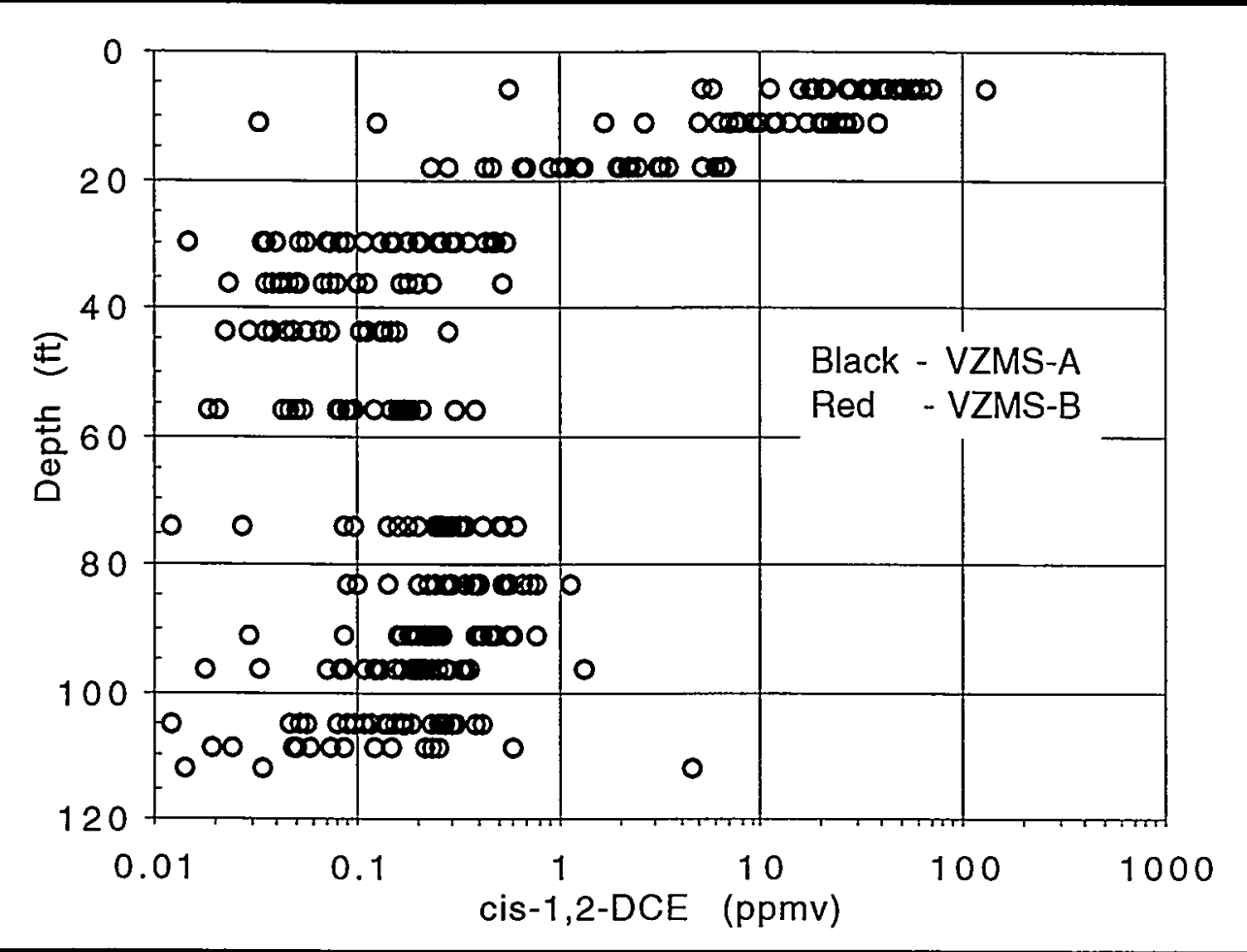

(b)

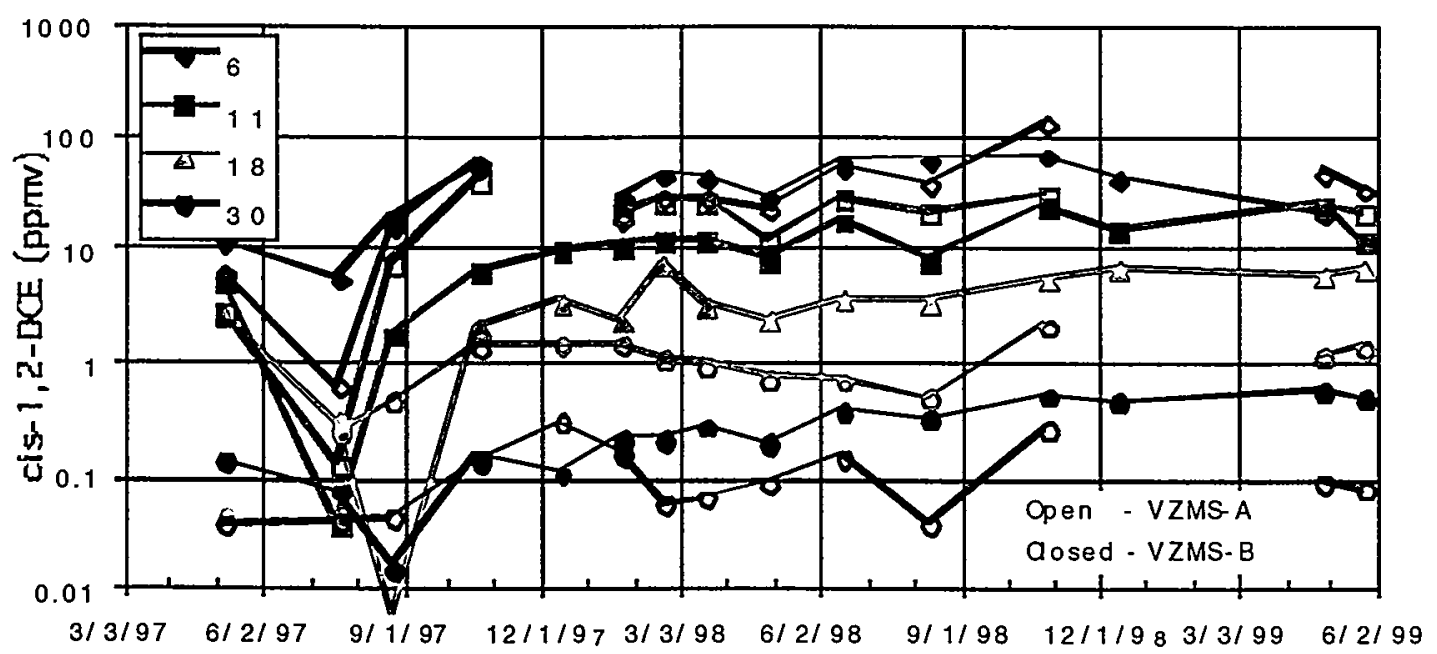

Figure 3.2. (a) Gas-phase cis-1,2 DCE concentration-depth profiles observed in Wells VZMS-A and VZMS-B at a series of times between May 1997 and May 1999; (b) Gas-phase cis$1,2 \mathrm{DCE}$ concentrations as a function of time for shallow observation depths. 


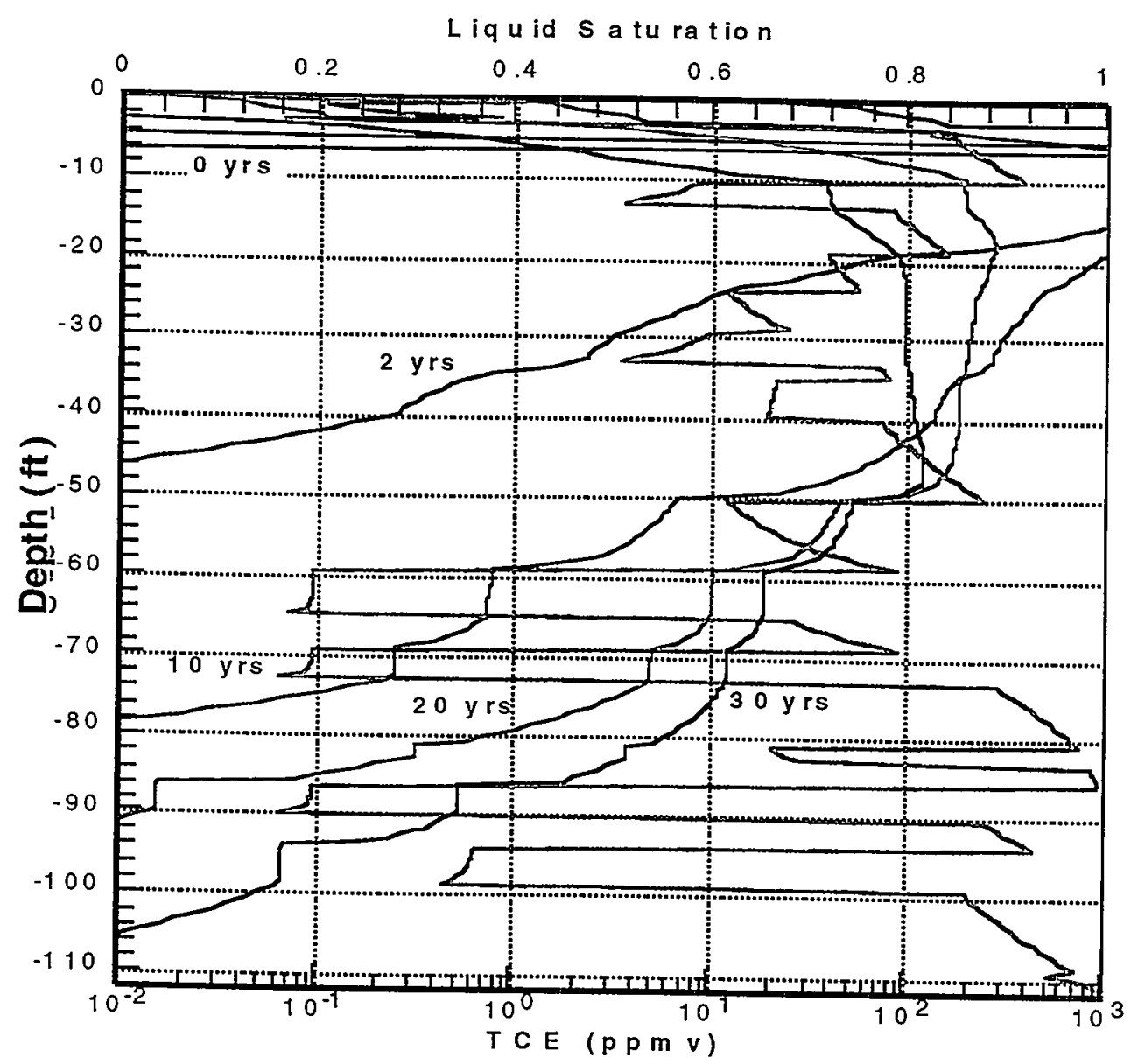

Figure 3.3. Simulated liquid saturation profile (green) and gas-phase TCE concentration profiles at the innermost column of an $(r, z)$ model for a 30-year simulation of TCE evolution. 


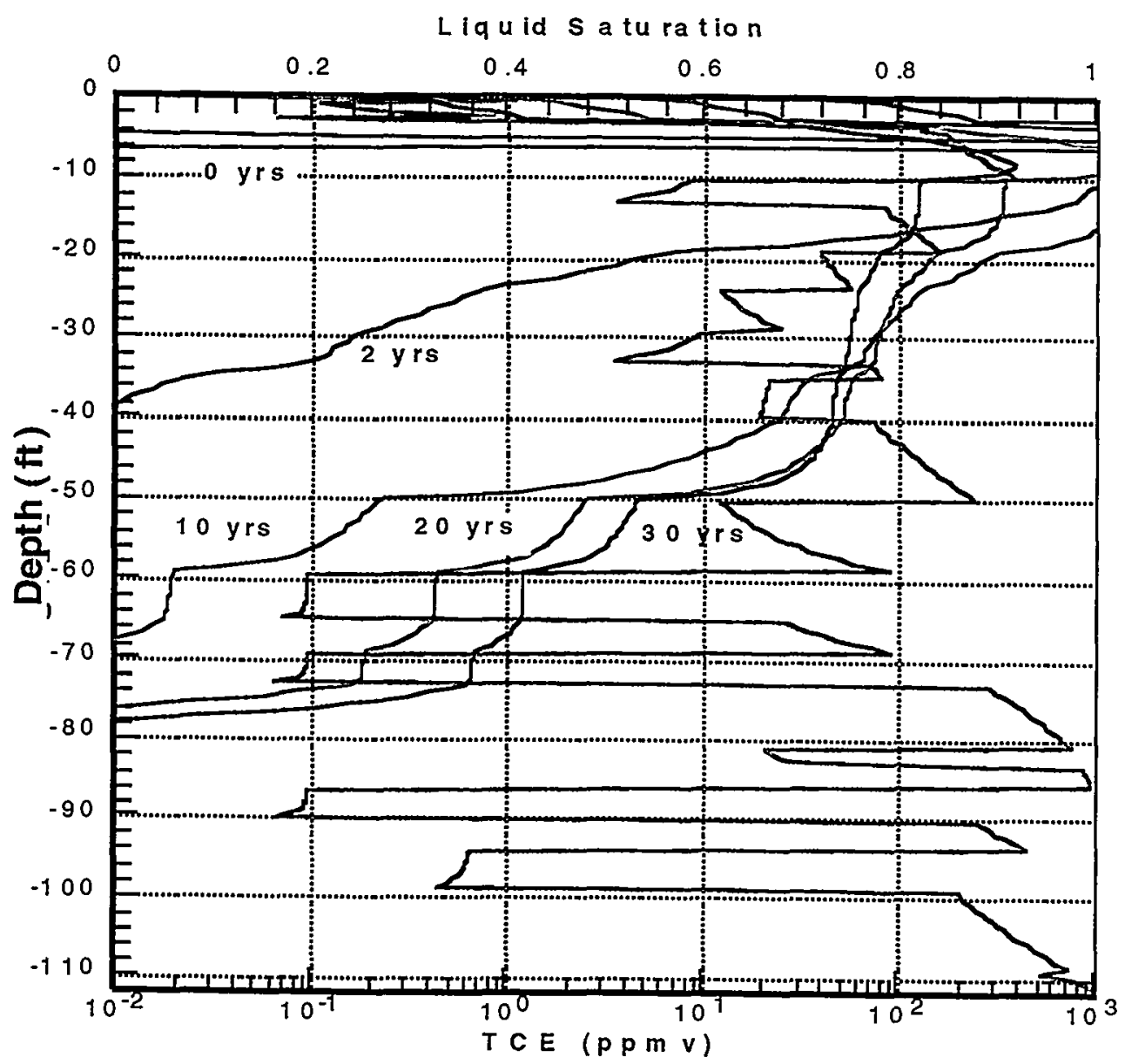

Figure 3.4. Simulated liquid saturation profile (green) and gas-phase TCE concentration profiles at the innermost column of an $(r, z)$ model for a 30-year simulation of TCE evolution with no liquid infiltration and immobile water. 


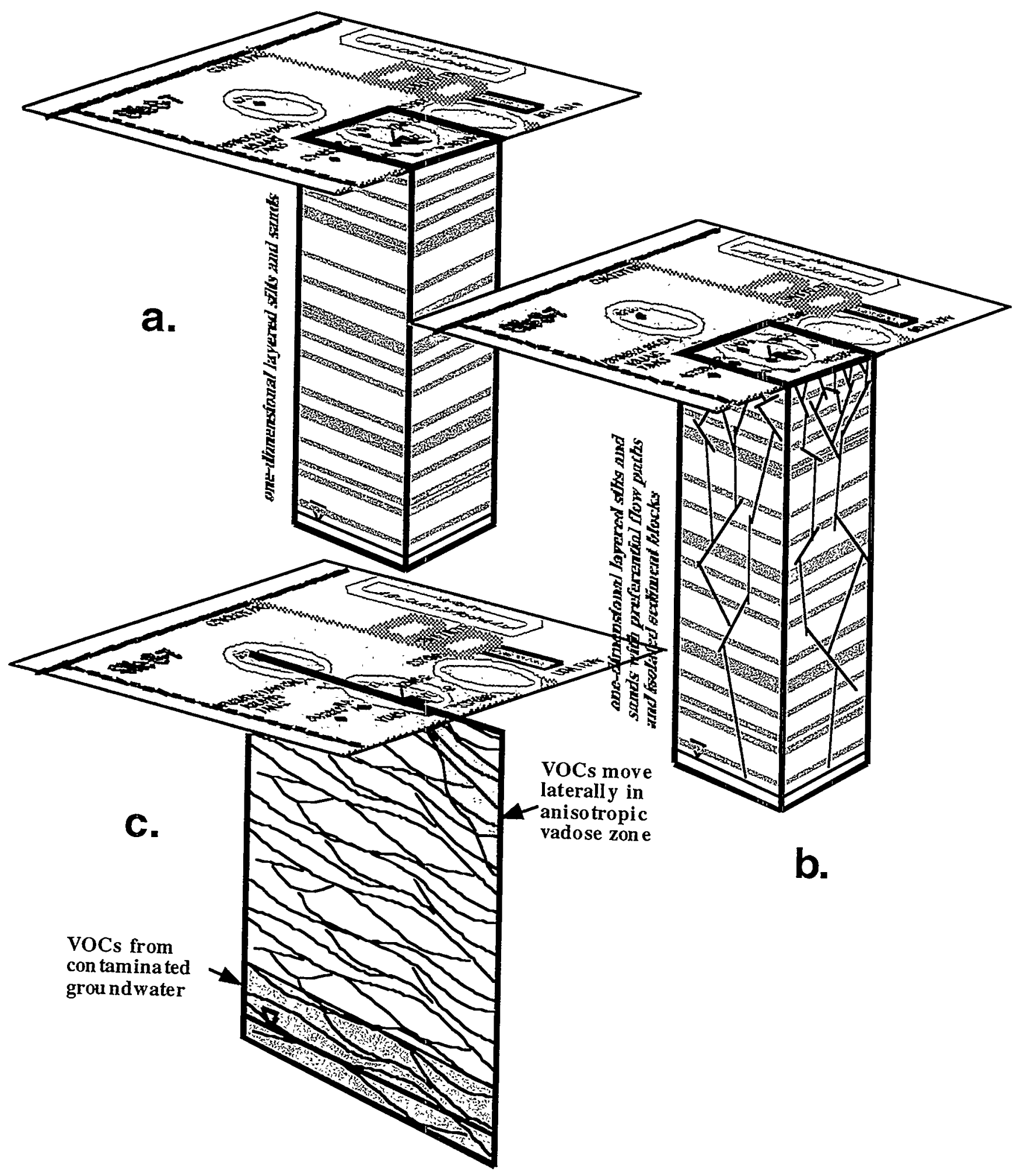

Figure 3.5. Conceptual models for subsurface flow and transport beneath site S-7. (a) Layered single-continuum model; (b) Layered dual-continua model with preferential flow paths (PFPs) and isolated sediment blocks (ISBs); (c) Anisotropic single-continuum model. 
$L$ iquid $S$ a tu ration

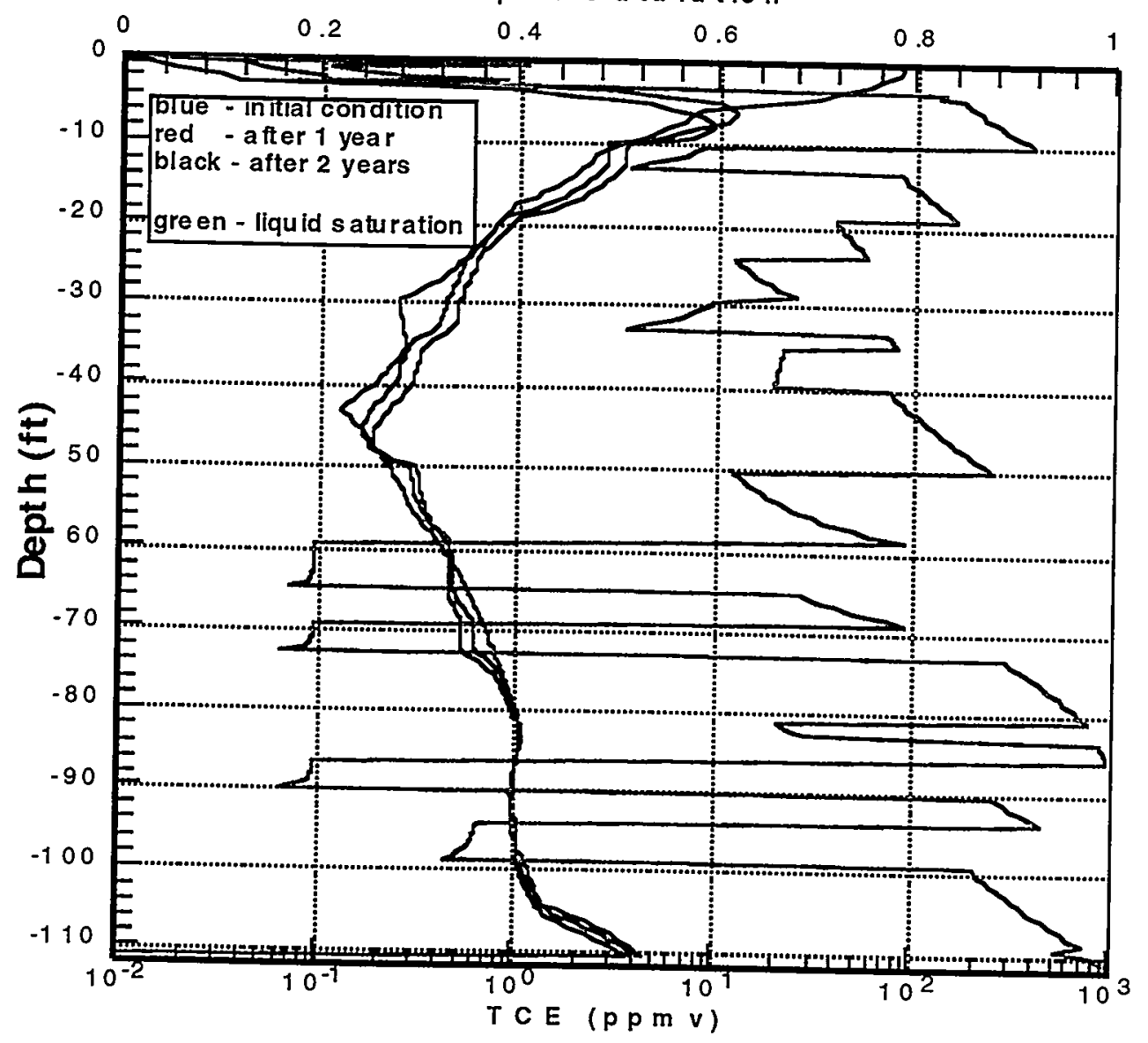

Figure 4.1. Gas-phase TCE concentration profiles for 1997-1999 simulation with singlecontinuum model, no NAPL in source. 


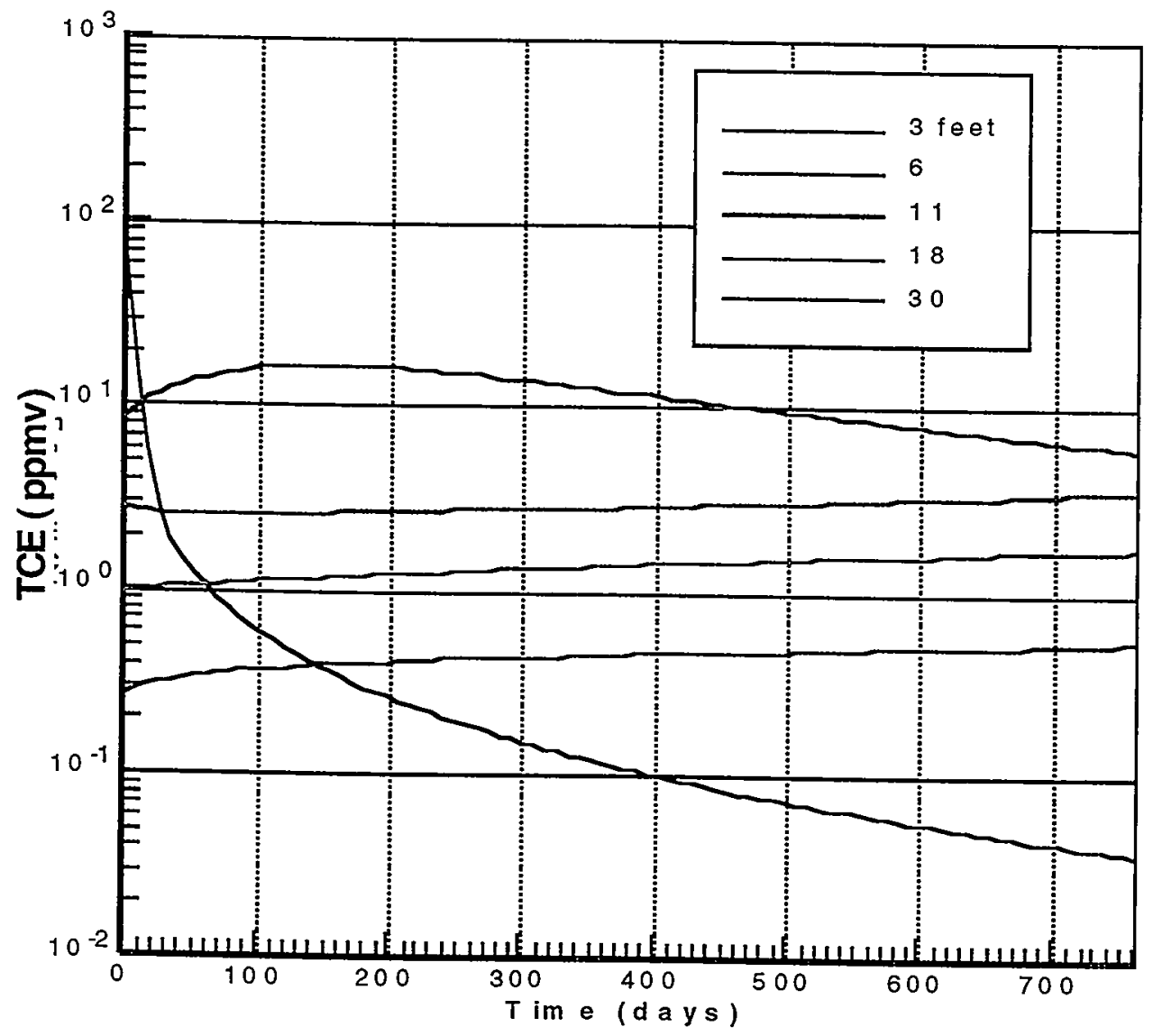

Figure 4.2. Gas-phase TCE concentration versus time for 1997-1999 simulation with singlecontinuum model, no NAPL in source. 
Liquid $S$ atu ration

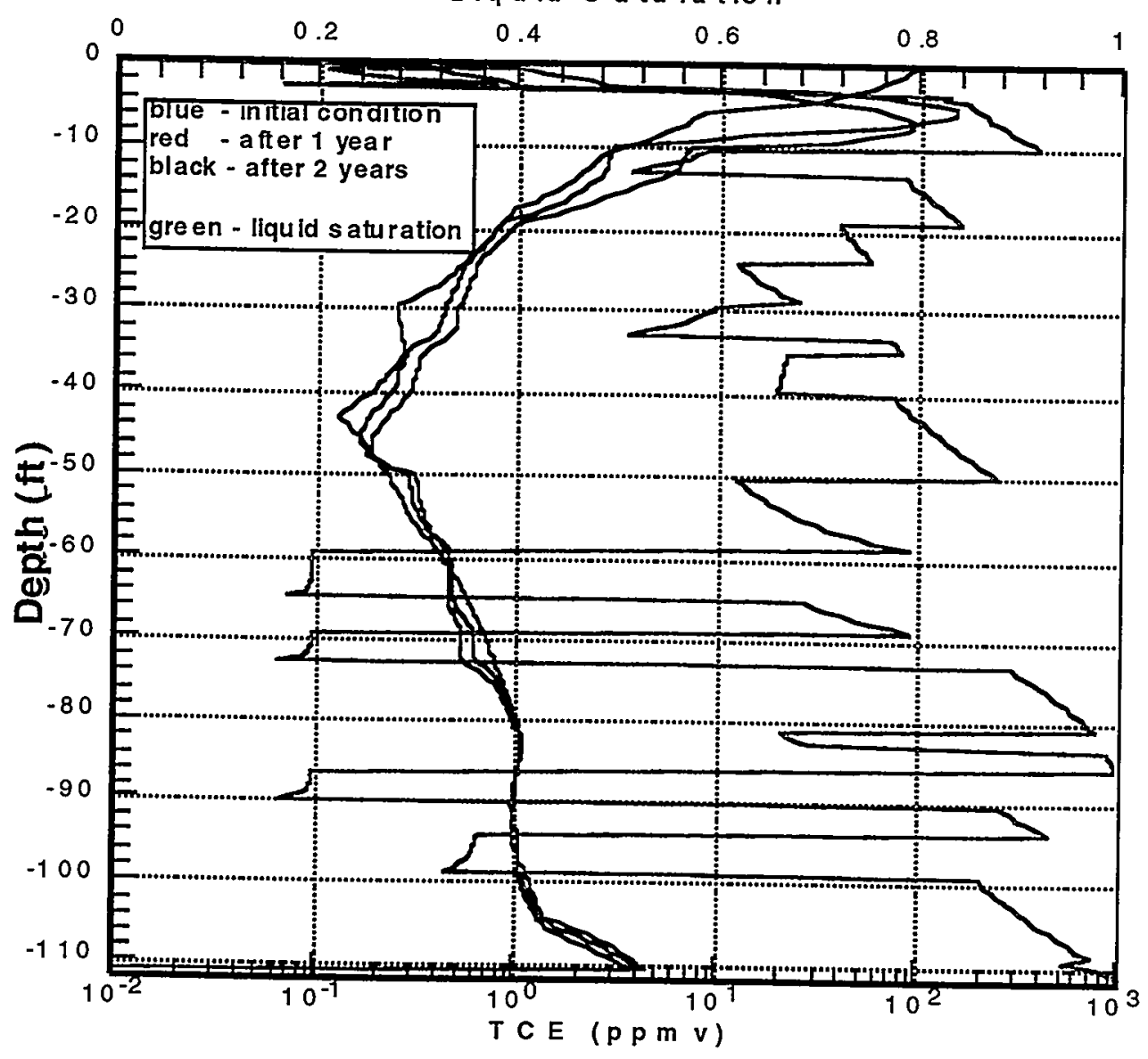

Figure 4.3. Gas-phase TCE concentration profiles for 1997-1999 simulation with singlecontinuum model, NAPL in source. 


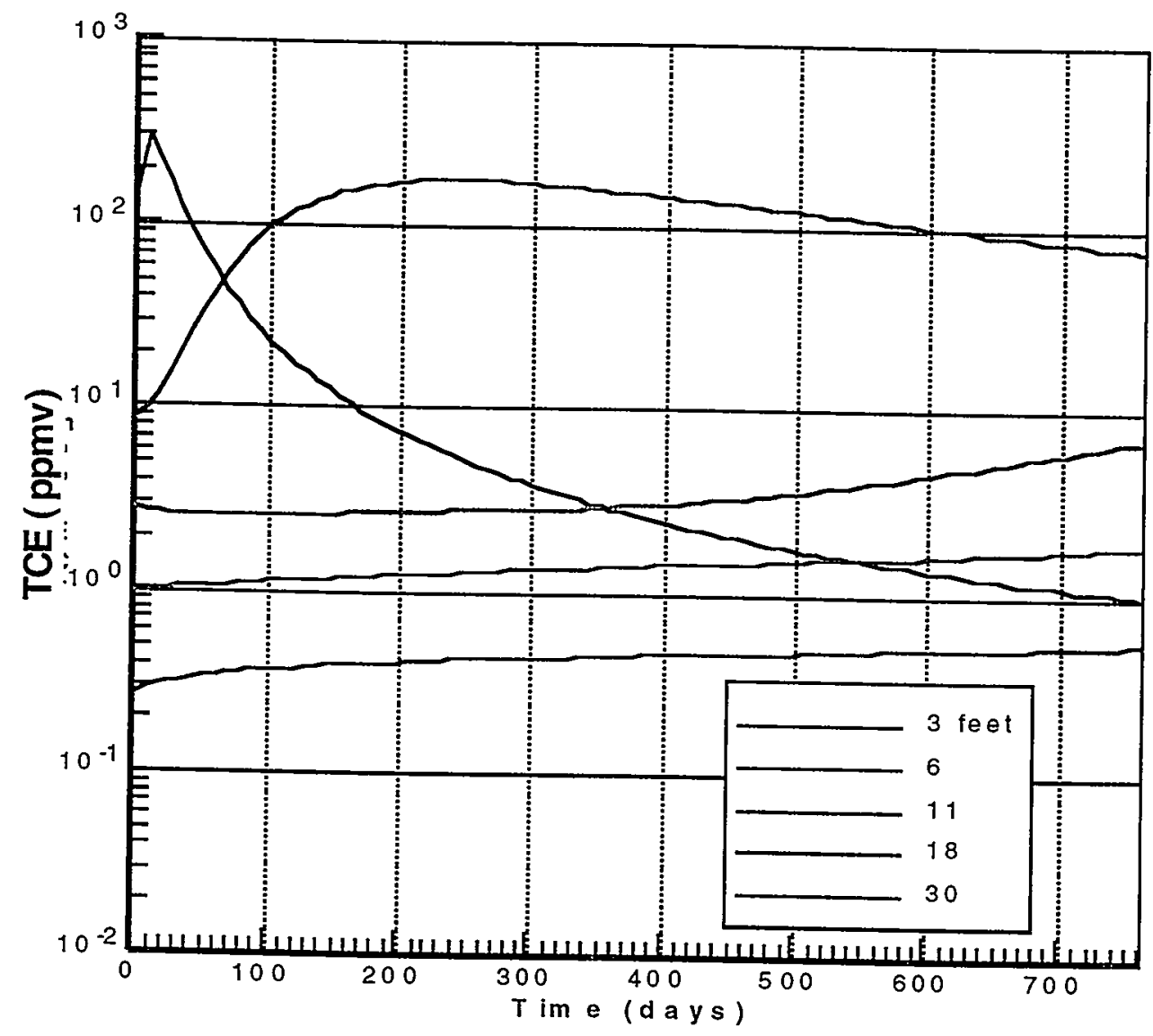

Figure 4.4. Gas-phase TCE concentration versus time for 1997-1999 simulation with singlecontinuum model, NAPL in source. 
(a)

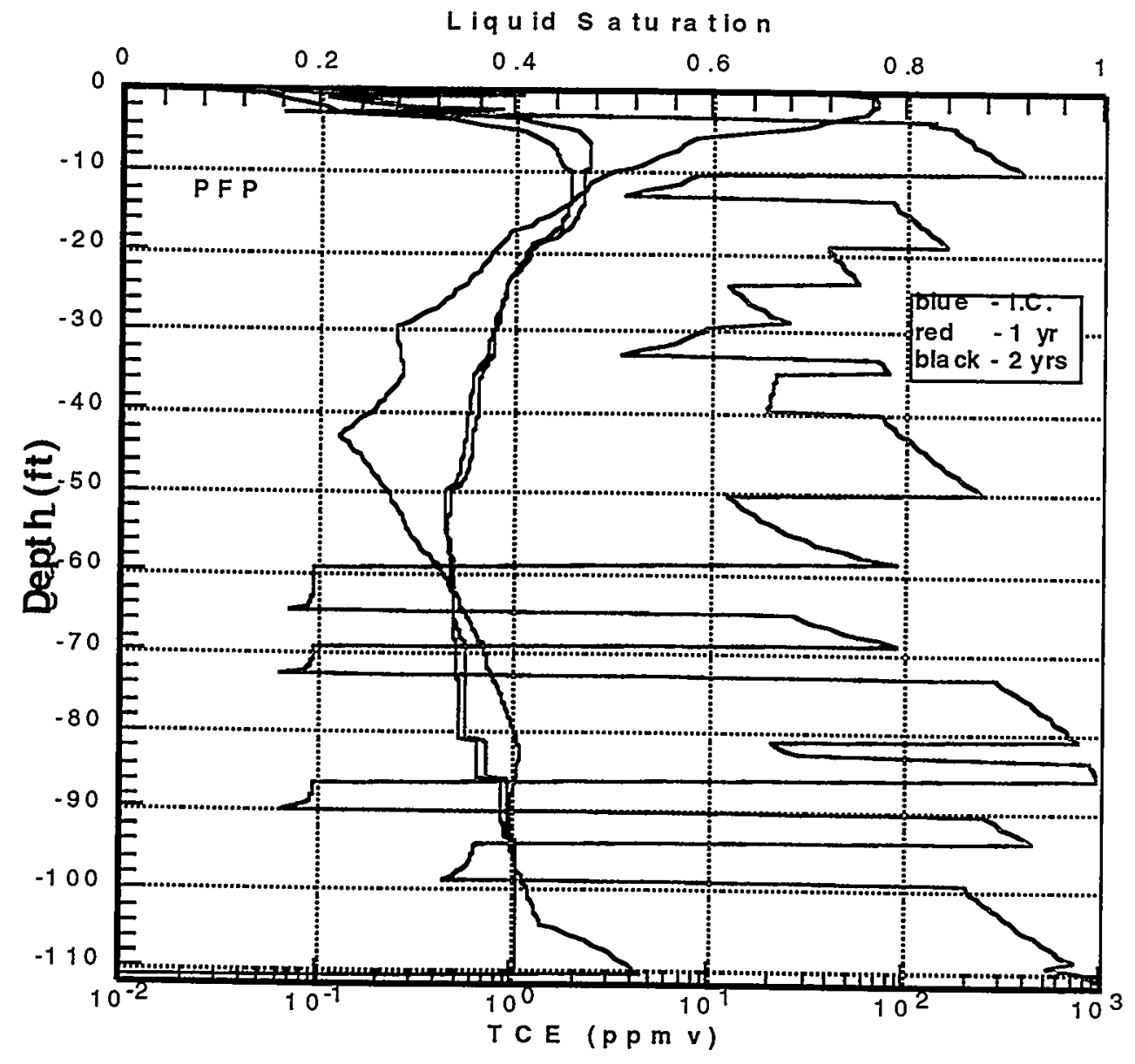

Figure 4.5. See caption on following page. 
(b)

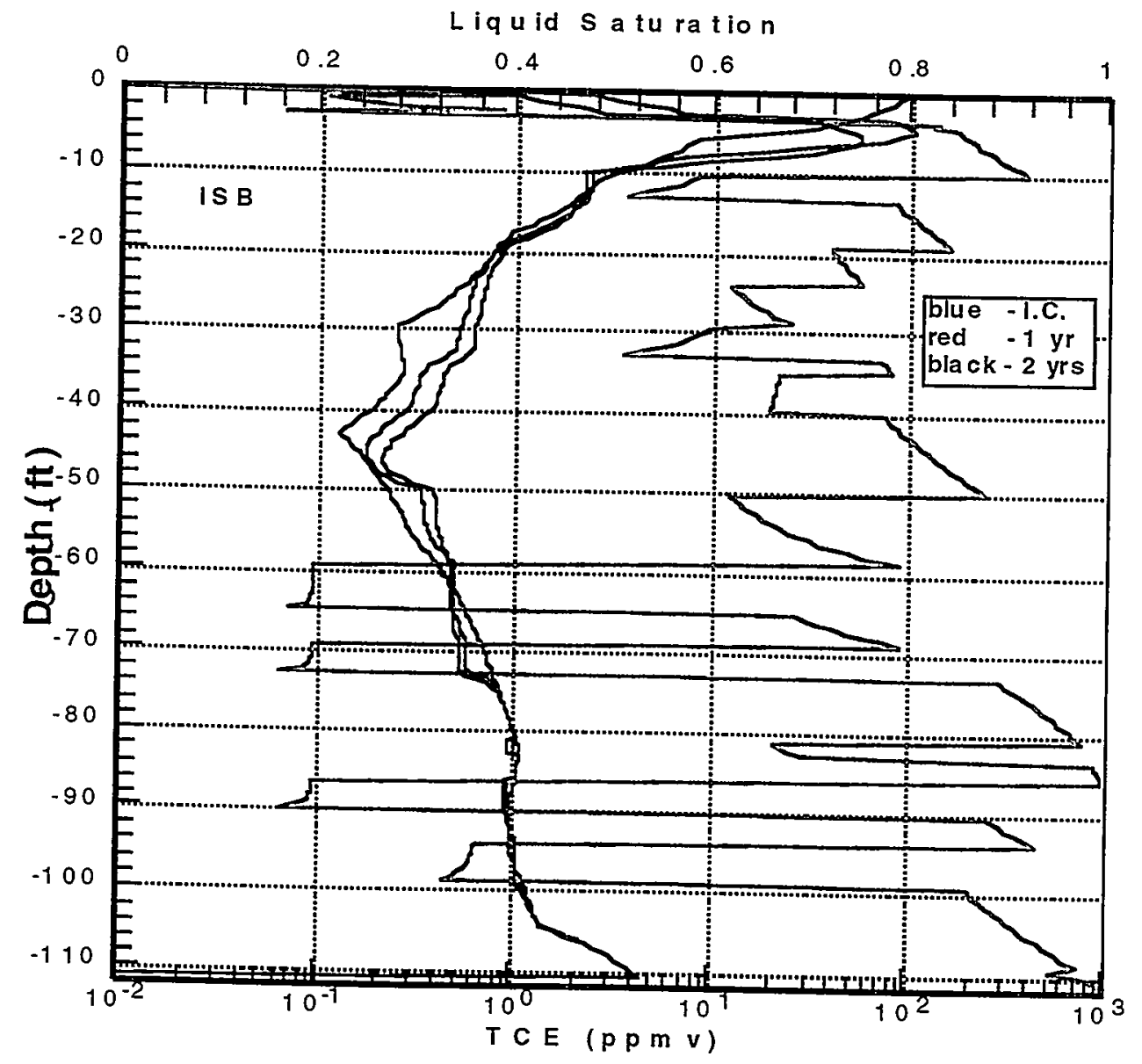

Figure 4.5. Gas-phase TCE concentration profiles for 1997-1999 simulation with dual-continua model, NAPL in source. (a) PFPs; (b) ISBs. 


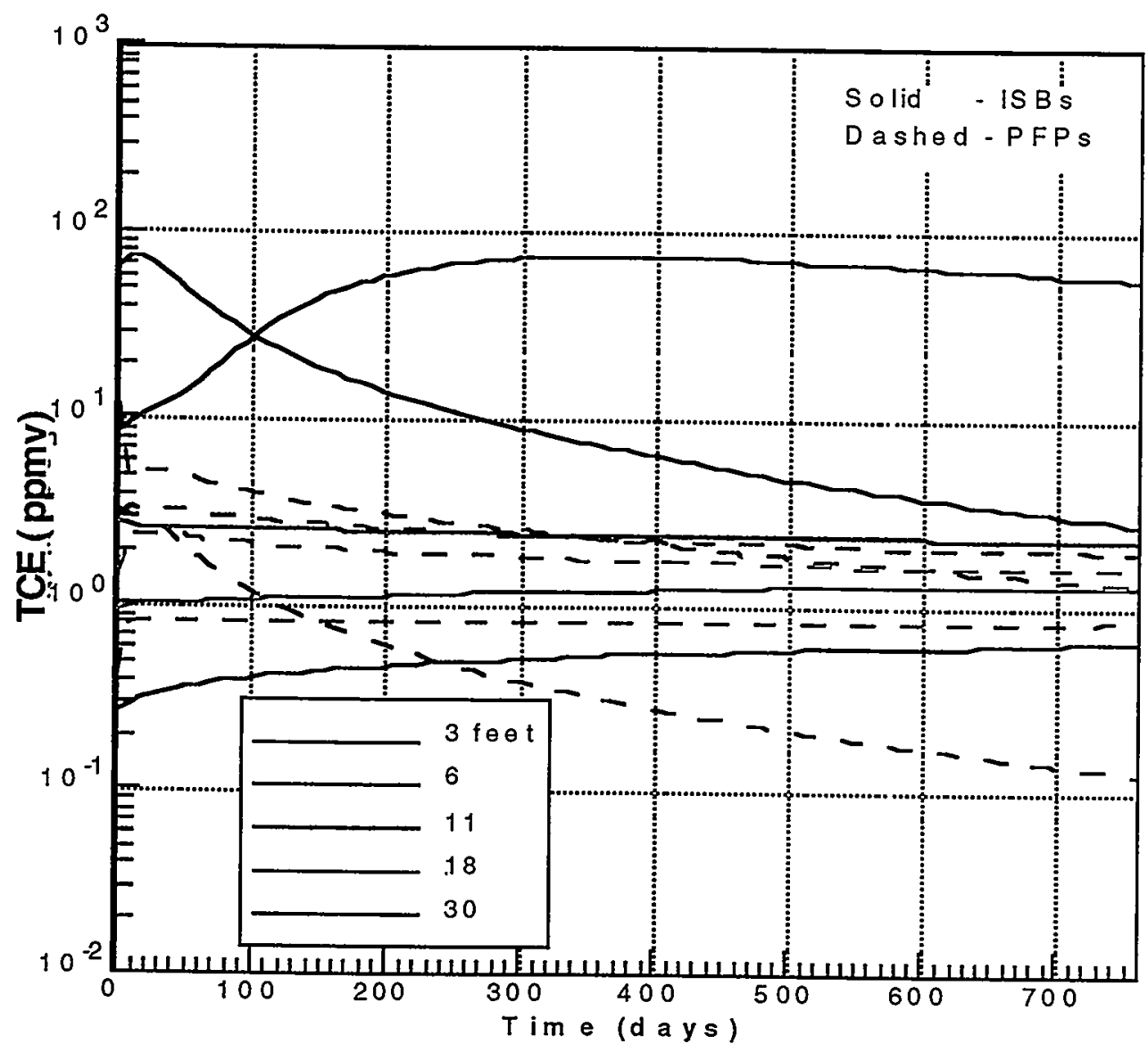

Figure 4.6. Gas-phase TCE concentration versus time for 1997-1999 simulation with dualcontinua model, NAPL in source. 


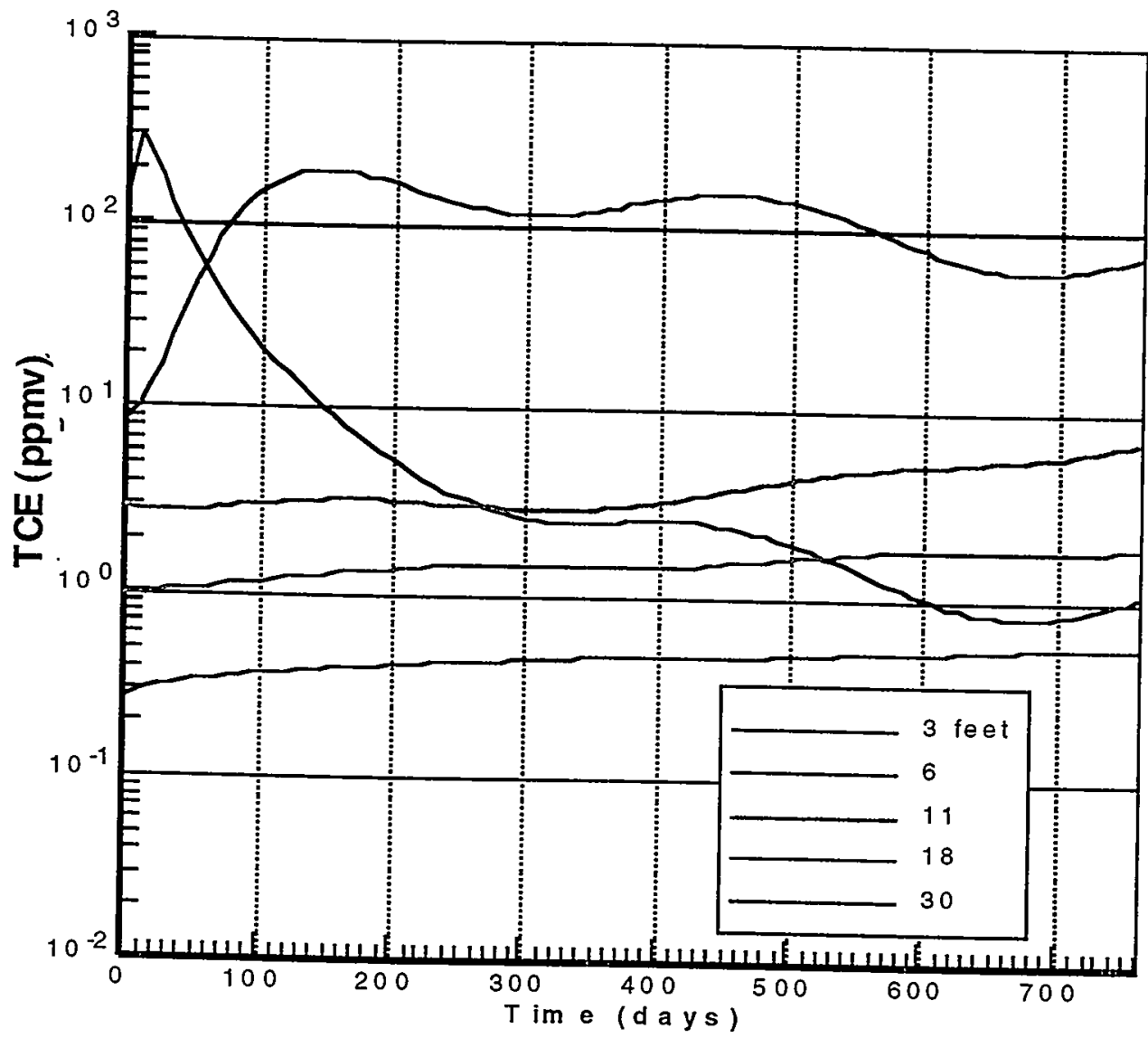

Figure 4.7. Gas-phase TCE concentration versus time for 1997-1999 simulation with singlecontinuum model, NAPL in source, and sinusoidally varying surface temperature. 


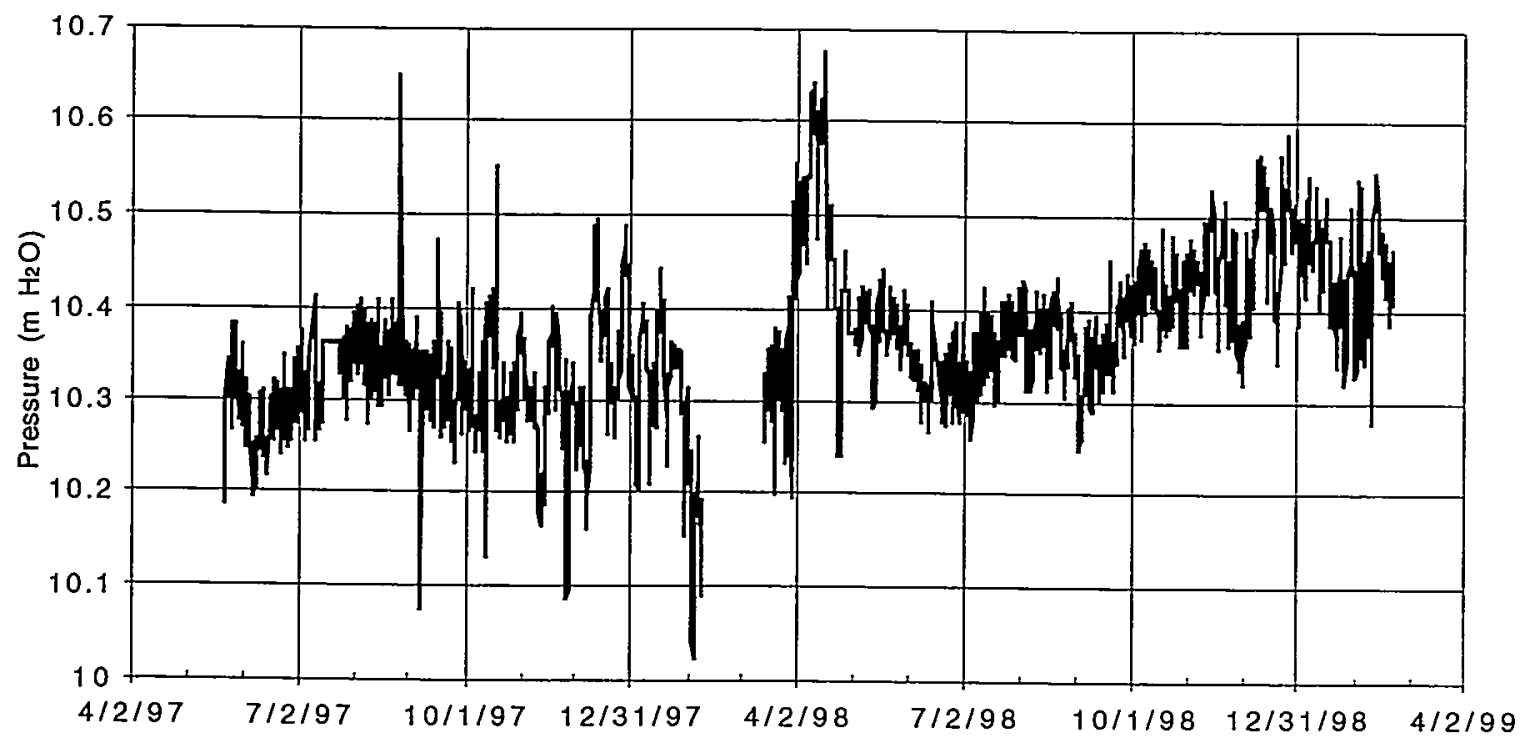

Figure 4.8. Atmospheric pressure variation during 1997-1999 at site S-7. 


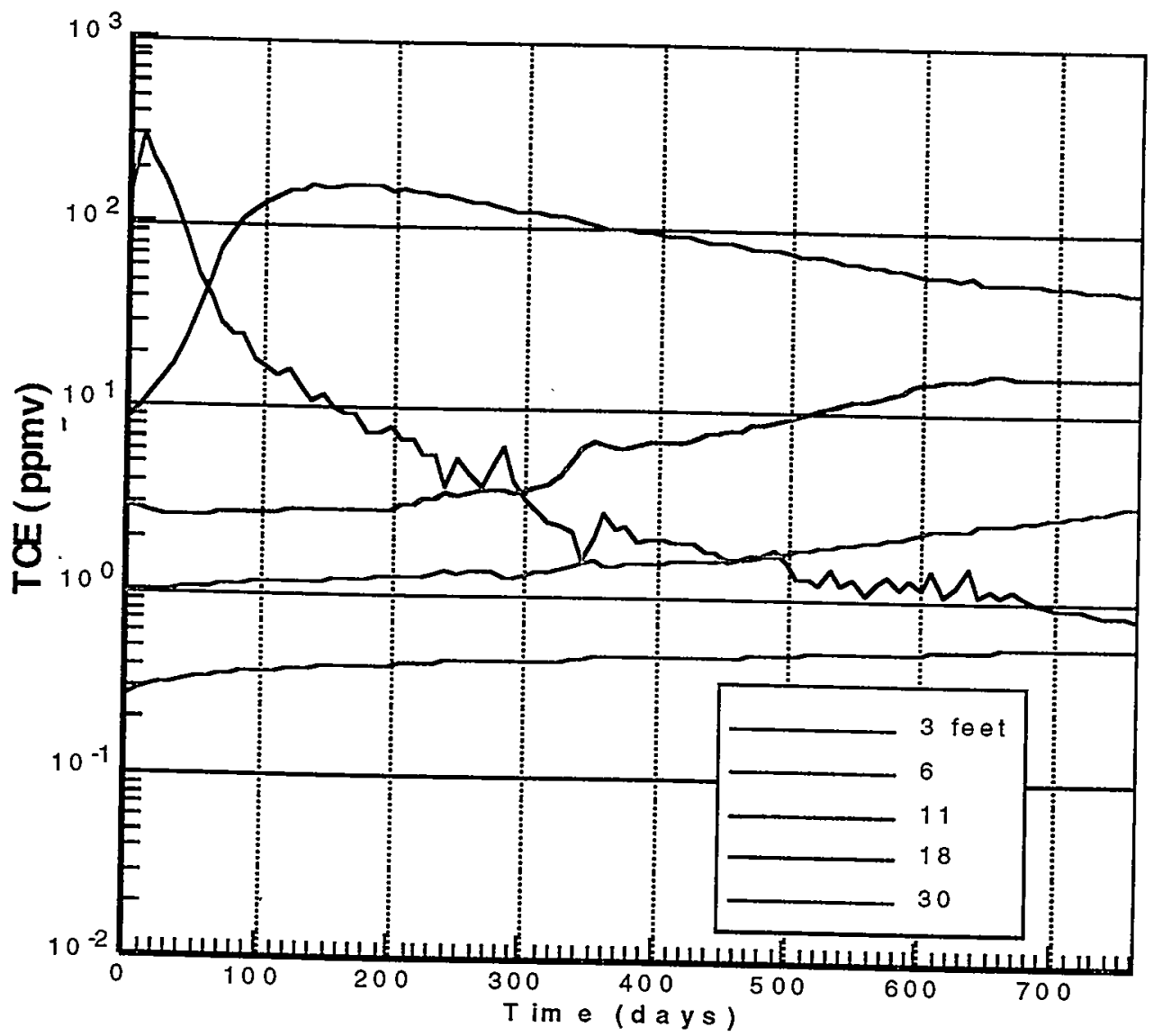

Figure 4.9. Gas-phase TCE concentration versus time for 1997-1999 simulation with singlecontinuum model, NAPL in source, and variable atmospheric pressure. 
(a) McClellan AFB Daily Precipitation
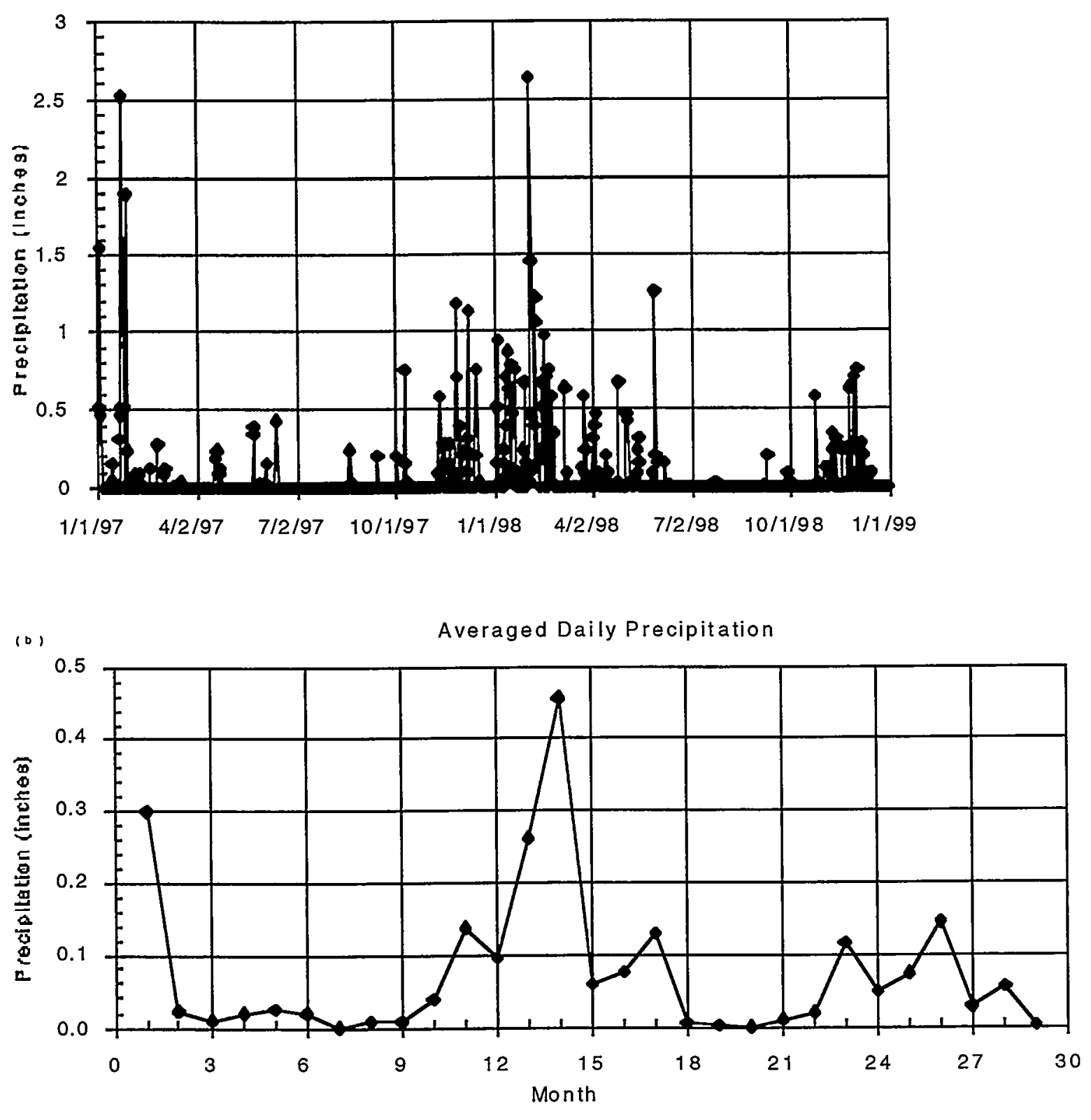

( Jan. ' $97=1 ;$ Jan. ' $98=13 ;$ Jan. ' $99=25$ )

Figure 4.10. (a) Daily precipitation for McClellan AFB; (b) Monthly average of daily precipitation (gaps in the McClellan AFB record are filled in with data from the Sacramento Airport and Sacramento Post Office). 


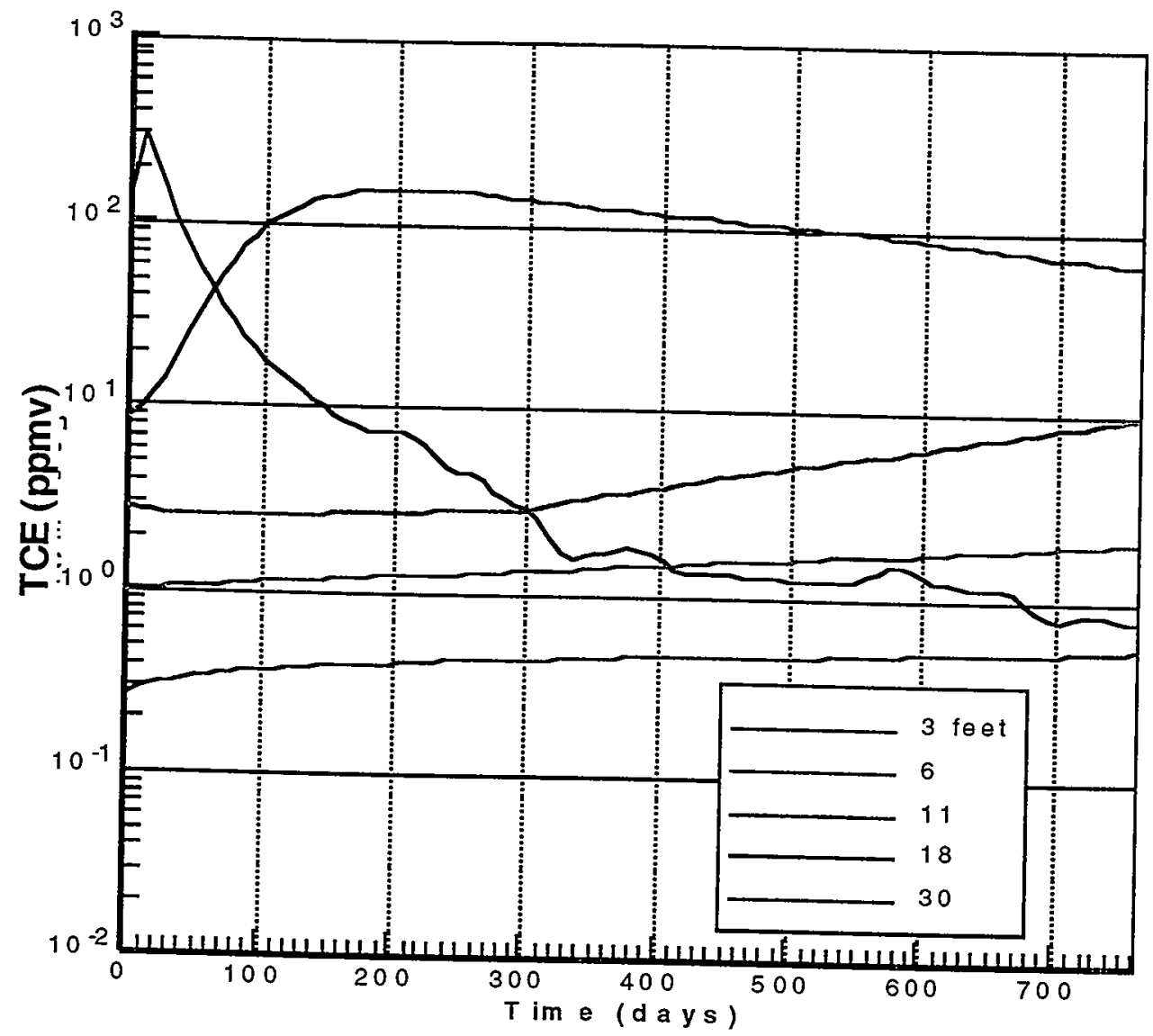

Figure 4.11. Gas-phase TCE concentration versus time for 1997-1999 simulation with singlecontinuum model, NAPL in source, and variable infiltration rate. 